\title{
Adsorption performance of an amine-functionalized MCM-41 mesoporous silica nanoparticle system for ciprofloxacin removal in a batch system
}

Tariq Al-Musawi ( $\square$ tariqjwad@yahoo.com )

Isra University/ Department of Civil Engineering

\section{Research Article}

Keywords: MCM-41-NH2, Ciprofloxacin, Adsorption study, Modeling, Regeneration test

Posted Date: May 25th, 2021

DOl: https://doi.org/10.21203/rs.3.rs-558931/v1

License: (c) (i) This work is licensed under a Creative Commons Attribution 4.0 International License.

Read Full License 


\section{Environmental Nanotechnology, Monitoring \& Management Adsorption performance of an amine-functionalized MCM-41 mesoporous silica nanoparticle system for ciprofloxacin removal --Manuscript Draft--}

\begin{tabular}{|c|c|}
\hline \multicolumn{2}{|l|}{ Manuscript Number: } \\
\hline Article Type: & Research Paper \\
\hline Keywords: & MCM-41-NH2; Ciprofloxacin; Adsorption study; Modeling; Regeneration test \\
\hline Corresponding Author: & $\begin{array}{l}\text { Tariq Al-Musawi } \\
\text { Isra University/ Department of Civil Engineering } \\
\text { Amman, Jordan Jordan }\end{array}$ \\
\hline First Author: & Ghaida Abu Rumman, Asst. Prof. \\
\hline \multirow[t]{4}{*}{ Order of Authors: } & Ghaida Abu Rumman, Asst. Prof. \\
\hline & Tariq Al-Musawi \\
\hline & Mika Sillanpaa, Prof. \\
\hline & Davoud Balarak, Prof. \\
\hline Abstract: & $\begin{array}{l}\text { Antibiotic pollutants discharged from pharmaceutical industries are often present in the } \\
\text { aquatic environment due to ineffective treatment of pharmaceutical wastewater and are } \\
\text { hazardous to human and aquatic life. Therefore, effective treatment of antibiotic- } \\
\text { containing wastewater is of utmost importance in the field of environmental protection. } \\
\text { This study aims to evaluate the adsorption performance of an amine-functionalized } \\
\text { MCM-41 mesoporous silica nanoparticles system (MCM-41-NH2) as an adsorbent for } \\
\text { the removal of ciprofloxacin (CIP) antibiotic from aqueous solution. Surface and } \\
\text { structural characteristics of MCM-41-NH2 were examined using scanning electron } \\
\text { microscopy, X-ray diffraction, Brunauer-Emmett-Teller analysis, Fourier transform } \\
\text { infrared spectroscopy, and point of zero charge analysis. In addition, thermal stability } \\
\text { was investigated by thermogravimetric analysis. Via the proposed treatment, } 99.25 \% \\
\text { CIP removal was achieved under the following conditions: pH = } 7 \text {; MCM-41-NH2 dose } \\
=0.8 \text { g/L; CIP concentration = } 10 \text { mg/L; adsorption time }=120 \text { min; and shaking speed } \\
=200 \text { rpm. Isotherm study showed that the experimental data fitted well with the } \\
\text { Langmuir equation. Moreover, the maximum adsorption capacity of MCM-41-NH2 for } \\
\text { CIP was } 164.3 \text { mg/g. Thermodynamic parameters showed that the adsorption process } \\
\text { of CIP on MCM-41-NH2 was endothermic and spontaneous. Additionally, the increase } \\
\text { in solution temperature had a positive impact on the removal of CIP. The kinetic data } \\
\text { obtained at different CIP concentrations (10, } 25,50 \text {, and } 100 \text { mg/L) were consistent } \\
\text { with the pseudo-second-order model. MCM-41-NH2 could be recycled eight times in } \\
\text { the proposed adsorption process, with a slight loss in its adsorption capacity. } \\
\text { Compared with other adsorbents, MCM-41-NH2 was more effective for CIP removal. }\end{array}$ \\
\hline \multirow[t]{3}{*}{ Suggested Reviewers: } & $\begin{array}{l}\text { Ahmed Mohammed, Prof. } \\
\text { Academia, University of Baghdad } \\
\text { ahmed.abd@coeng.uobaghdad.edu.iq } \\
\text { Recently, Dr. Ahmed has published numerous articles related to the removal of } \\
\text { hazardous materials from wastewater using nano-adsorbents. Therefore, reviewing our } \\
\text { work will be in the direction of his interest. }\end{array}$ \\
\hline & $\begin{array}{l}\text { Abeer AlWard, Prof. } \\
\text { Lecturer, University of Baghdad } \\
\text { Dr.abeer.wared@coeng.uobaghdad.edu.iq } \\
\text { Dr. Abeer, a highly experienced scientist in the field of sorption treatment, has reported } \\
\text { several studies describing advanced treatments for water and wastewater. }\end{array}$ \\
\hline & $\begin{array}{l}\text { Sama Al-Jubouri, Asst. Prof. } \\
\text { Lecturer, University of Baghdad } \\
\text { sama.al-jubouri@coeng.uobaghdad.edu.iq } \\
\text { Dr. Sama, a highly experienced scientist in the field of advanced purification } \\
\text { technologies, has published several studies on the removal of hazardous pollutants } \\
\text { from water and wastewater. }\end{array}$ \\
\hline
\end{tabular}


Sami Guiza, Prof.

Lecturer, University of Gabes: Universite de Gabes

Sami_guiza@yahoo.fr

Prof. Sami Guiza has wide experience in the field of environmental analysis and in the field of research on the effects of micropollutants as well as fluid interactions with porous media.

\section{Opposed Reviewers:}


To,

Prof. Dr. Piero Gardinali,

Editors-in-Chief

Environmental Nanotechnology, Monitoring and Management

Dear Editor:

I wish to submit a research article for publication in Environmental Nanotechnology, Monitoring and Management "Adsorption performance of an amine-functionalized MCM-41 mesoporous silica nanoparticle system for ciprofloxacin removal."

In this study, an amine-functionalized MCM-41 mesoporous silica nanoparticle system (MCM-41- $\left.\mathrm{NH}_{2}\right)$ was prepared by modifying MCM-41 mesoporous silica nanoparticle via amination and applied as an adsorbent for the removal of ciprofloxacin from aqueous solutions. The behavior and ciprofloxacin removal efficiency of $\mathrm{MCM}-41-\mathrm{NH}_{2}$ in the suggested treatment were investigated. Results show that $\mathrm{MCM}-41-\mathrm{NH}_{2}$ is an active and recyclable adsorbent for the removal of ciprofloxacin and may be a promising treatment agent for practical applications such as the treatment of antibiotic-containing wastewater.

We believe that the present study is suitable for publication in your journal because of journal's particular focus on research related to the application of new adsorbents in the field of environmental nanotechnology for water and wastewater treatment.

This manuscript has not been published or presented elsewhere in part or in entirety and is not under consideration by another journal. In addition, prior to submission, we used Elsevier's Language Editing services to ensure that our manuscript is free of grammatical, spelling, and other common errors (Project nr. 205789).

Thank you for your consideration. I look forward to hearing from you.

Yours sincerely,

Dr. Davoud Balarak

Corresponding author

Email: dbalarak2@gmail.com 
- MCM-41- $\mathrm{NH}_{2}$ was prepared and used as an adsorbent for ciprofloxacin removal

- The removal efficiency was investigated using different physicochemical parameters

- Isotherm, kinetic, and thermodynamic studies were conducted

- $\mathrm{MCM}-41-\mathrm{NH}_{2}$ acts as an effective adsorbent and is recyclable

- $99.25 \%$ ciprofloxacin removal efficiency was achieved under optimum conditions 


\section{Preparation}

\section{MCM41}

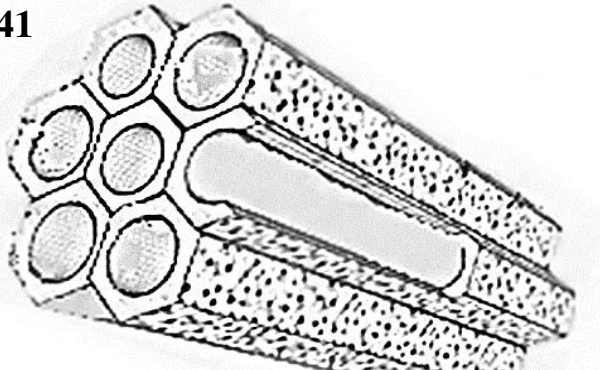

MCM41

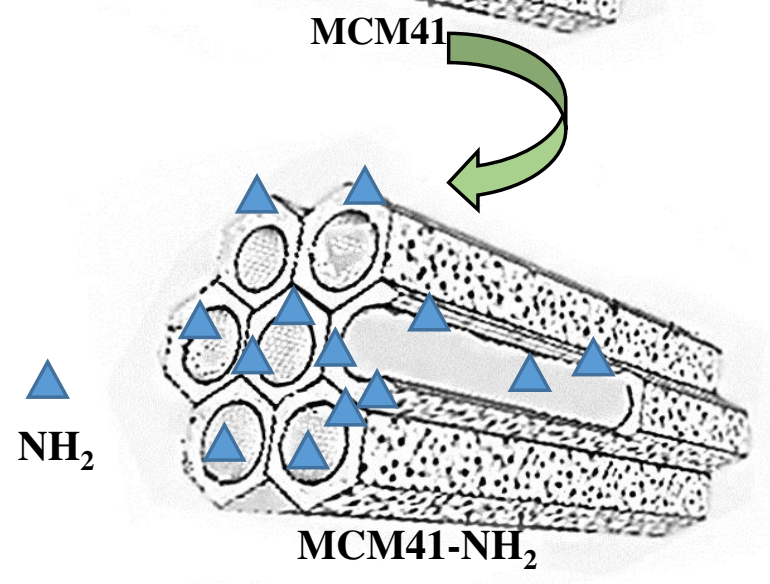

MCM41-NH
Characterization analyses
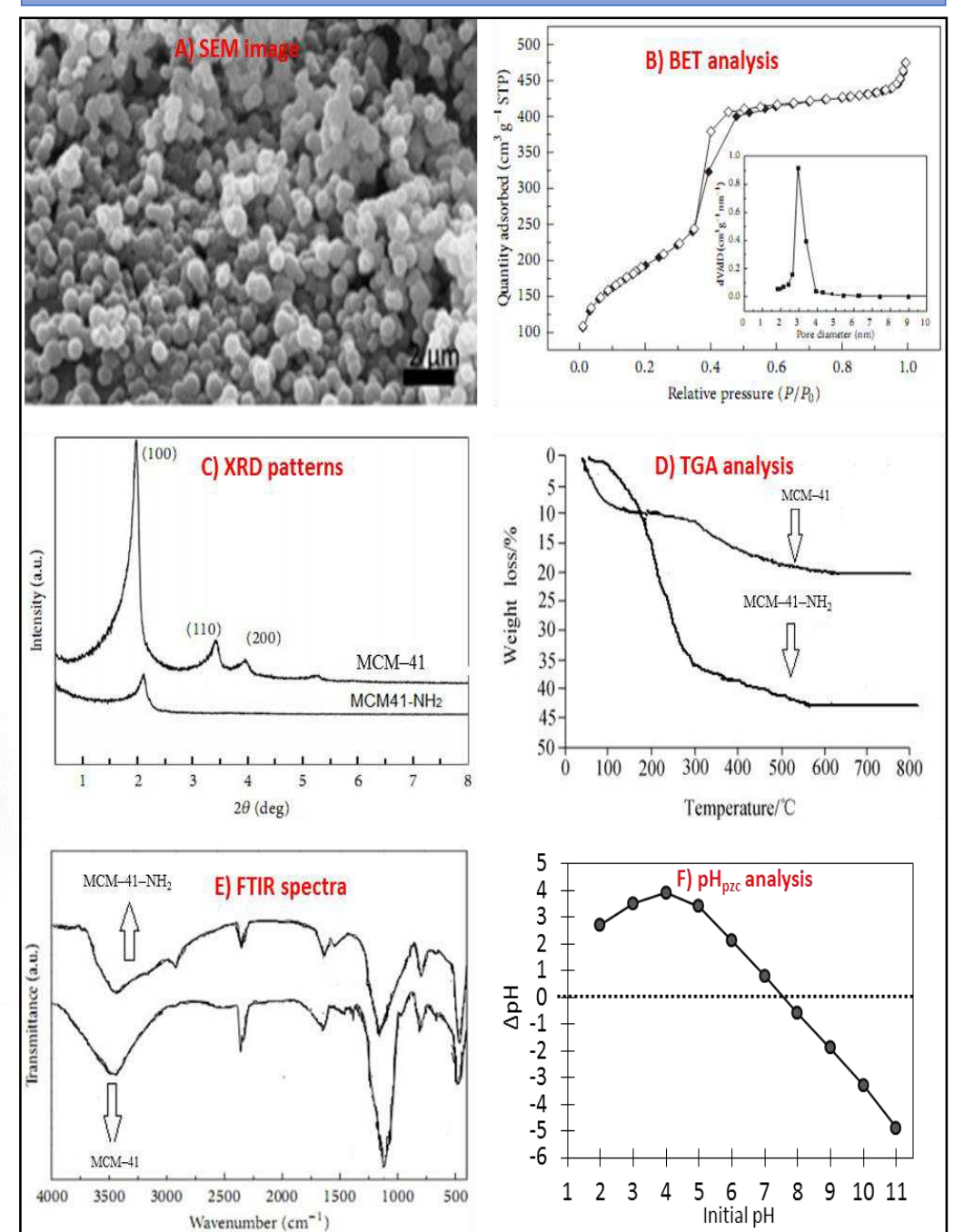

Adsorption analyses for ciprofloxacin
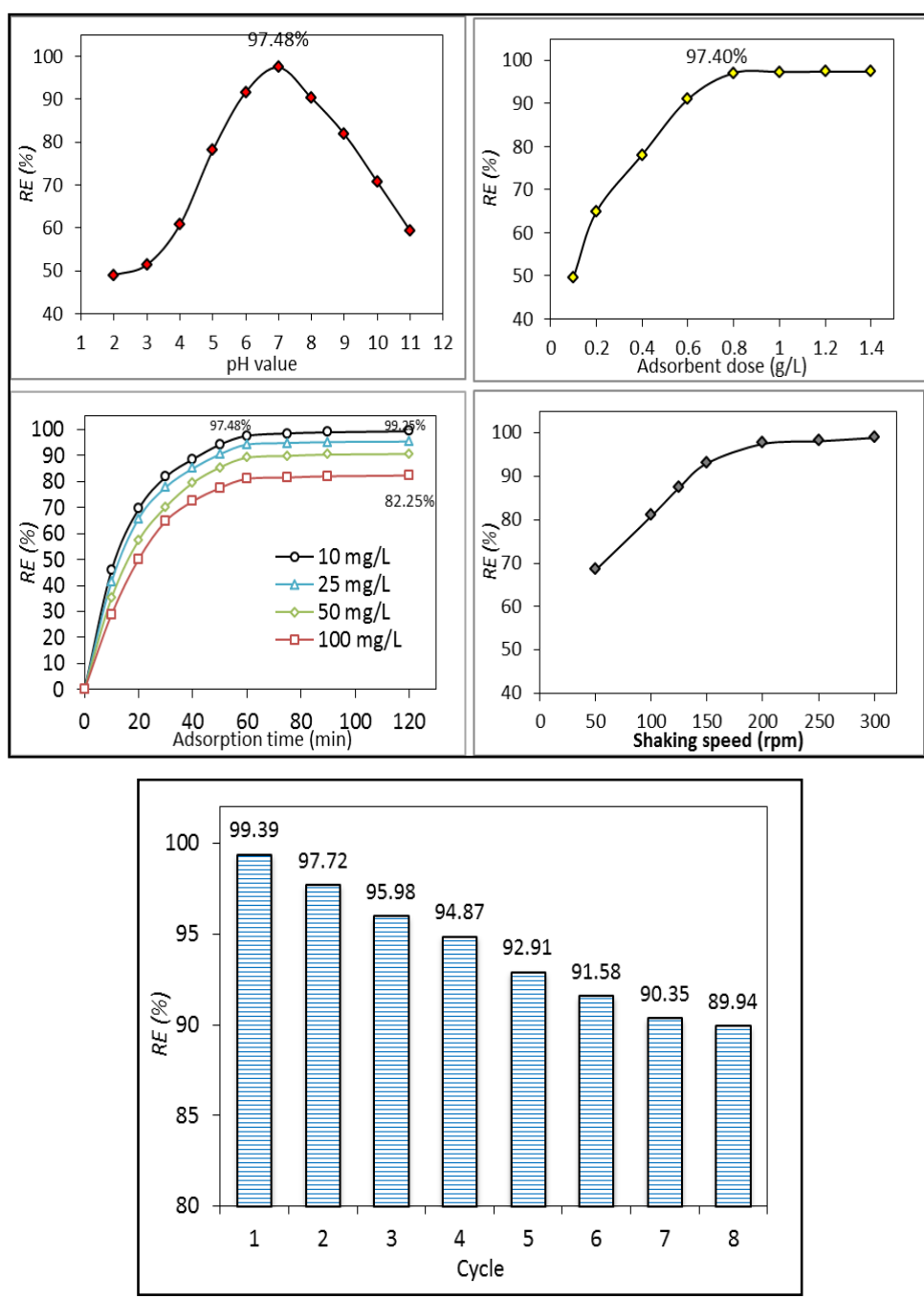


\title{
Adsorption performance of an amine-functionalized MCM-41 mesoporous silica nanoparticle system for ciprofloxacin removal
}

\author{
Ghaida Abu Rumman ${ }^{1}$, Tariq J. Al-Musawi ${ }^{1}$, Mika Sillanpaa ${ }^{2,3}$, Davoud Balarak ${ }^{4, *}$ \\ ${ }^{1}$ Department of Civil Engineering, Faculty of Engineering, Isra University, Amman, Jordan \\ ${ }^{2}$ School of Civil Engineering and Surveying, Faculty of Health, Engineering and Sciences, \\ University of Southern Queensland, West Street, Toowoomba, 4350 QLD, Australia \\ ${ }^{3}$ Department of Chemical Engineering, School of Mining, Metallurgy and Chemical \\ Engineering, University of Johannesburg, P. O. Box 17011, Doornfontein 2028, South Africa \\ ${ }^{4}$ Department of Environmental Health, Health Promotion Research Center, Zahedan University \\ of Medical Sciences, Zahedan, Iran \\ *Corresponding author. Email: dbalarak2@gmail.com
}




\begin{abstract}
Antibiotic pollutants discharged from pharmaceutical industries are often present in the aquatic environment due to ineffective treatment of pharmaceutical wastewater and are hazardous to human and aquatic life. Therefore, effective treatment of antibiotic-containing wastewater is of utmost importance in the field of environmental protection. This study aims to evaluate the adsorption performance of an amine-functionalized MCM-41 mesoporous silica nanoparticles system (MCM-41- $\left.\mathrm{NH}_{2}\right)$ as an adsorbent for the removal of ciprofloxacin (CIP) antibiotic from aqueous solution. Surface and structural characteristics of $\mathrm{MCM}-41-\mathrm{NH}_{2}$ were examined using scanning electron microscopy, X-ray diffraction, Brunauer-Emmett-Teller analysis, Fourier transform infrared spectroscopy, and point of zero charge analysis. In addition, thermal stability was investigated by thermogravimetric analysis. Via the proposed treatment, $99.25 \%$ CIP removal was achieved under the following conditions: $\mathrm{pH}=7 ; \mathrm{MCM}-41-\mathrm{NH}_{2}$ dose $=0.8 \mathrm{~g} / \mathrm{L}$; CIP concentration $=10 \mathrm{mg} / \mathrm{L}$; adsorption time $=120 \mathrm{~min}$; and shaking speed $=200 \mathrm{rpm}$. Isotherm study showed that the experimental data fitted well with the Langmuir equation. Moreover, the maximum adsorption capacity of $\mathrm{MCM}-41-\mathrm{NH}_{2}$ for CIP was $164.3 \mathrm{mg} / \mathrm{g}$. Thermodynamic parameters showed that the adsorption process of CIP on MCM-41- $\mathrm{NH}_{2}$ was endothermic and spontaneous. Additionally, the increase in solution temperature had a positive impact on the removal of CIP. The kinetic data obtained at different CIP concentrations (10, 25, 50 , and $100 \mathrm{mg} / \mathrm{L})$ were consistent with the pseudo-second-order model. $\mathrm{MCM}-41-\mathrm{NH}_{2}$ could be recycled eight times in the proposed adsorption process, with a slight loss in its adsorption capacity. Compared with other adsorbents, $\mathrm{MCM}-41-\mathrm{NH}_{2}$ was more effective for CIP removal.
\end{abstract}

Keywords: MCM-41- $\mathrm{NH}_{2}$; Ciprofloxacin; Adsorption study; Modeling; Regeneration test 


\section{Introduction}

Studies on wastewater treatment and reuse are particularly important as they provide viable solutions for the prevention of environmental pollution (Balarak and Azarpira, 2016, Liu et al., 2011). Currently, one of the most dangerous and most widespread pollutants in the environment is antibiotics, which are common pollutants in pharmaceutical wastewater (Zhao et al., 2014). Several studies have reported that in the last decade, the production rate of antibiotics in pharmaceutical factories has increased from 100 thousand tons/year to 200 thousand tons/year (Serwecińska, 2020, Miranda et al., 2018). For example, ciprofloxacin (CIP) is widely administered to humans and animals for the treatment of bacterial infections, specifically urinary tract, respiratory, and gastrointestinal infections (Peng et al., 2016, Amini et al., 2010). In fact, pollution of ecosystems by antibiotics or their by-products can pose serious risks to human health because of the high toxicity and carcinogenic properties of these compounds (Mohammed et al., 2020b, Nasseh et al., 2020). Therefore, it is critical to find an appropriate treatment for the removal of these compounds from pharmaceutical wastewater before reusing or discharging this wastewater into water bodies.

Various treatments, including ozonation, nanofiltration, oxidation, photocatalytic degradation, biological methods, and adsorption, have been used alone or as complementary processes for the treatment of pharmaceutical wastewater (Gao and Pedersen, 2005, Peterson et al., 2012, Chang et al., 2012, Nasseh et al., 2020, Nasseh et al., 2021). Among the abovementioned techniques, the adsorption method has received significant attention than other treatment techniques because of its many advantages such as low initial cost, simple and flexible design, possibility of effluent reuse, easy operation, and insensitivity to toxic pollutants. In addition, intermediate by-products are not generated during this treatment (Balarak and Mostafapour, 2019, Balarak and Azarpira, 
2016). Major mechanisms responsible for the removal of pollutants by the adsorption process include electrostatic processes, ion exchange, bonding processes, and chemical reactions (Mahvi et al., 2018). Several adsorbents, such as activated carbon, have an excellent ability to adsorb organic pollutants from air, water, and soil (Brouers and Al-Musawi, 2020, Brouers and AlMusawi, 2015). The adsorption ability of activated carbon is attributed to its superior characteristics including a mesoporous structure and large surface area (Rahardjo et al., 2011). Because of the high cost and the loss of part of activated carbon during treatment, numerous researchers are working on developing new alternatives that do not have these shortcomings (Moussavi et al., 2013, Kerkez-Kuyumcu et al., 2016). From these perspectives, the use of nanotechnology in the adsorption process has increased due to the small size, and thus high adsorption ability of nanoparticles (Al-Jubouri et al., 2018, Samarghandi et al., 2015). Furthermore, several nanoadsorbents have high regeneration rates, which reduce the treatment cost (Kim et al., 2010).

Mesoporous silica has been used in many practical applications such as catalysis, drug transfer, and adsorption (Li et al., 2017, Yokoi et al., 2012). Accordingly, mesoporous silica nanoparticles have been considered as effective adsorbents for the removal of different pollutants. Main adsorption properties of mesoporous silica are high surface area, strong functional groups, structural stability, surface modification, and a regular channel structure (Lam et al., 2008, Bui and Choi, 2009). Moreover, this type of adsorbents has a negatively charged surface owing to the presence of silanol (Si-OH) groups; thus, these adsorbents are more useful for the adsorption of cations (Heidari et al., 2009). Santa Barbara Amorphous 15 (SBA-15) and Mobil Composition of Matter No. 41 (MCM-41) mesoporous silica nanoparticles are potential adsorbents because of their favorable surface and structural properties (Ebrahimi Getkesh et al., 2014). To enhance the 
adsorption capacity $\left(q_{t}\right)$ and kinetics of MCM-41, modification or functionalization of the pore walls of MCM-41 is considered a simple and effective way (Çıtak et al., 2012). In this direction, the amination of $\mathrm{MCM}-41\left(\mathrm{MCM}-41-\mathrm{NH}_{2}\right)$ has received substantial attention because amine group has a positive impact on the performance of the adsorption systems of heavy metals, dyes, and other recalcitrant organic compounds (Heidari et al., 2009, Ebrahimi Getkesh et al., 2014). As very few studies have been performed on the elimination of antibiotics using silicate nanoparticles, the purpose of this study was to investigate the $q_{t}$ and behavior of MCM-41- $\mathrm{NH}_{2}$ toward CIP. Surface and structural properties of $\mathrm{MCM}-41-\mathrm{NH}_{2}$ with respect to adsorption were examined by advanced analyses. The effects of $\mathrm{pH}, \mathrm{MCM}-41-\mathrm{NH}_{2}$ dose $(M / V(\mathrm{~g} / \mathrm{L}))$, CIP concentration, adsorption time $(t, \mathrm{~min})$, shaking speed, temperature on the CIP removal efficiency $(R E(\%))$ of $\mathrm{MCM}-41-\mathrm{NH}_{2}$ were also analyzed. In addition, isotherm, kinetic, and thermodynamic studies were comprehensively conducted. Finally, the regeneration of MCM41- $\mathrm{NH}_{2}$ was evaluated in several CIP adsorption-desorption cycles.

\section{Materials and Methods}

\subsection{Chemicals}

To synthesize $\mathrm{MCM}-41-\mathrm{NH}_{2}, \quad$ analytical-grade chemicals were used including cetyltrimethylammonium bromide (CTMAB), normal hexane, sodium hydroxide, 37\% hydrochloric acid, (3-aminopropyl) trimethoxysilane (3-APTMS), $0.1 \mathrm{M}$ potassium nitrate, and chloride acid (Merck, Germany). Powdered CIP (0.5 kg) was purchased from Sigma-Aldrich (Germany), and its physiochemical characteristics are listed in Table 1. All the above-mentioned chemicals were of high purity and were directly used without further purification. In addition, deionized water $\left(\mathrm{pH}=6-8\right.$ and conductivity $\left.\leq 4.3 \mu \mathrm{S} . \mathrm{cm}^{-1}\right)$ at $25{ }^{\circ} \mathrm{C}$ was employed for the 
preparation and dilution of CIP working solutions and for mixing the chemicals (Merck, Germany).

Table 1. Physiochemical characteristics of ciprofloxacin (CIP) used in the present study

\begin{tabular}{lllll}
\hline Molecular & $\lambda_{\max }$ & Molecular & $\mathbf{p K a}$ & Structure \\
Weight & & Formula & &
\end{tabular}

\begin{tabular}{llll}
\hline $331.35 \mathrm{~g} / \mathrm{mol}$ & $270 \mathrm{~nm}$ & $\mathrm{C}_{17} \mathrm{H}_{18} \mathrm{FN}_{3} \mathrm{O}_{3}$ & 6.1 and 8.7
\end{tabular}

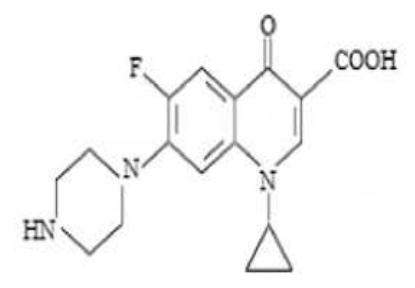

\subsection{Preparation of MCM-41}

MCM-41 was prepared by the method reported in the literature (Lam et al., 2008). First, $0.64 \mathrm{~g}$ sodium hydroxide was dissolved in $27 \mathrm{~mL}$ deionized water. Then, $1.8 \mathrm{~g} \mathrm{SiO}_{2}$ nanoparticles were vigorously mixed with the as-prepared sodium hydroxide solution at $80{ }^{\circ} \mathrm{C}$ for $3 \mathrm{~h}$ to ensure complete dissolution. After cooling the resulting $\mathrm{SiO}_{2}$ solution to ambient temperature, CTMAB (5.46 g) was added to it followed by vigorous stirring for $1 \mathrm{~h}$ until a highly viscous homogeneous solution was acquired. Next, $0.3 \mathrm{~mL} \mathrm{HCl}$ was added to the resulting mixture, and the reaction was allowed to proceed for $10 \mathrm{~min}$. Thereafter, $24 \mathrm{~mL}$ deionized water was added, and at this stage, a white gel was obtained, which was stirred for $2 \mathrm{~h}$ at $300 \mathrm{rpm}$. The resulting mixture was then transferred to a polypropylene container and placed in an oven at $100{ }^{\circ} \mathrm{C}$ for 3 days. Finally, after being cooled to ambient temperature, the resulting solution was filtered using a typical filter, and the supernatant (MCM-41) was collected in a container. Subsequently, MCM-41 was 
washed several times with deionized water followed by drying at $100{ }^{\circ} \mathrm{C}$ for $12 \mathrm{~h}$. Calcination of MCM-41 was carried out in two stages: at $105^{\circ} \mathrm{C}$ for $2 \mathrm{~h}$ and at $540{ }^{\circ} \mathrm{C}$ for $6 \mathrm{~h}$.

\subsection{Preparation of $\mathrm{MCM}-41-\mathrm{NH}_{2}$}

Amination of MCM-41 was performed according to a previously reported method (Ho et al., 2003). Initially, $2.5 \mathrm{~g}$ calcined MCM-41 was soaked in $50 \mathrm{~mL}$ hexane for approximately $1 \mathrm{~h}$. Next, 2.5 g 3-APTMS was mixed with the MCM-41 solution. The resulting mixture was refluxed for $6 \mathrm{~h}$ followed by cooling to ambient temperature. Subsequently, the solution was filtered, washed twice with $20 \mathrm{~mL}$ hexane, dried, and then placed in a desiccator for further use.

\subsection{Characterization}

Surface and structural properties with respect to the adsorption behavior of $\mathrm{MCM}-41-\mathrm{NH}_{2}$ were investigated using precise devices and powerful techniques. Pore size specifications and surface area of $\mathrm{MCM}-41-\mathrm{NH}_{2}$ were determined by Brunauer-Emmett-Teller (BET) analysis using Belsorp mini II (Bel Japan Co.). Functional groups were analyzed by Fourier transform infrared (FTIR) spectroscopy (PerkinElmer, Spectrum GX). X-ray diffraction (XRD) (X'Pert Pro MPD) was conducted to examine the crystallographic characteristics of the adsorbent, and XRD patterns were achieved in the $2 \theta$ range from $20^{\circ}$ to $80^{\circ}$ at a wavelength of $1.5 \AA$. High-resolution scanning electron microscopy (SEM) was performed using a TESCAN microscope (MIRA3$\mathrm{XMU}$ ) for characterizing the morphology of $\mathrm{MCM}-41-\mathrm{NH}_{2}$. In addition, the thermal stabilities of MCM-41 and MCM-41- $\mathrm{NH}_{2}$ were measured by evaluating the weight loss of these materials with an increase in temperature from $50{ }^{\circ} \mathrm{C}$ to $800{ }^{\circ} \mathrm{C}$ using a thermal analyzer (Model: Q600, TA Co.).

\subsection{Determination of point of zero charge $\left(\mathrm{pH}_{\mathrm{pzc}}\right)$}


$\mathrm{pH}_{\mathrm{pzc}}$ is also an important and fundamental indicator of the characteristics of a material and is calculated to determine the net charge of an adsorbent as a function of solution $\mathrm{pH}$. Moreover, the determination of $\mathrm{pH}_{\mathrm{pzc}}$ is an essential step in investigating the variation in the adsorption mechanism of the adsorbent with a change in the $\mathrm{pH}$ of the pollutant solution. In the present study, the $\mathrm{pH}_{\mathrm{pzc}}$ of $\mathrm{MCM}-41-\mathrm{NH}_{2}$ was evaluated using a previously reported method (AlMusawi et al., 2020).

\subsection{Experiments}

Experiments on the adsorption of CIP on $\mathrm{MCM}-41-\mathrm{NH}_{2}$ were conducted in a batch adsorption system using several 200-mL Erlenmeyer flasks filled with $100 \mathrm{~mL}$ CIP solution. Adsorption reactions were performed by shaking these flasks in a shaker at $150 \mathrm{rpm}$ for $120 \mathrm{~min}$. Thereafter, the adsorption performance of $\mathrm{MCM}-41-\mathrm{NH}_{2}$ toward CIP removal was tested at varying physicochemical parameters: $\mathrm{pH}: 2-11 ; M / V: 0.1-1.4 \mathrm{~g} / \mathrm{L}$; initial CIP concentration $\left(C_{0}(\mathrm{mg} / \mathrm{L})\right)$ : 25-100 mg/L; $t: 0-120 \mathrm{mg} / \mathrm{L}$; shaking speed: 0-200 rpm; and temperature: $20-60{ }^{\circ} \mathrm{C}$. For the isotherm study, an experiment was conducted to determine the relationship between the equilibrium adsorption capacity $\left(q_{e}(\mathrm{mg} / \mathrm{g})\right)$ of $\mathrm{MCM}-41-\mathrm{NH}_{2}$ and CIP concentration at different temperatures (283-328 K). Furthermore, for kinetic and thermodynamic studies, the experimental data of the analysis of the effects of $C_{0}$ and temperature on the $q_{t}$ of MCM-41$\mathrm{NH}_{2}$ were used. At a specific $t$, a $5 \mathrm{~mL}$ sample was taken from each flask and centrifuged at $1509 \mathrm{x} \mathrm{g}$ for $10 \mathrm{~min}$. The concentration of CIP in the supernatant was measured using highperformance liquid chromatography (HPLC) under the following conditions: an ODS C18 column; a UV detector; three mobile phases: $0.025 \mathrm{M}$ orthophosphoric acid, methanol, and acetonitrile at a 13:75:12 ratio; wavelength: $280 \mathrm{~nm}$; retention time: $5.5 \mathrm{~min}$; and inflow: $1 \mathrm{~mL}$ $\min ^{-1}$. The collected samples were measured three times using HPLC, and the average values 
were adopted in the calculations. $q_{t}$ and $R E$ of $\mathrm{MCM}-41-\mathrm{NH}_{2}$ for CIP were determined using Equations (1) and (2), respectively (Li et al., 2017, Wang et al., 2016):

$q_{t}=\frac{C_{0}-C_{t}}{M / V}$

$R E(\%)=\frac{\left(C_{0}-C_{t}\right)}{C_{0}} \times 100$

where $M / V$ denotes the MCM-41- $\mathrm{NH}_{2}$ dose $(\mathrm{g} / \mathrm{L})$, and $C_{0}$ and $C_{t}$ are the CIP concentration $(\mathrm{mg} / \mathrm{L})$ in solution before and after specific time of adsorption process $(t, \mathrm{~min})$, respectively. The concentration and adsorption capacity at equilibrium time is denoted by $C_{e}(\mathrm{mg} / \mathrm{L})$ and $q_{e}$ $(\mathrm{mg} / \mathrm{g})$, respectively.

\section{Results and Discussion}

\subsection{Characterization of $\mathrm{MCM}-41-\mathrm{NH}_{2}$}

Figure $1(\mathrm{~A}-\mathrm{F})$ shows the results of the characterization analyses performed on MCM-41 and MCM-41- $\mathrm{NH}_{2}$ samples in this study. Morphological and surface characteristics of MCM-41$\mathrm{NH}_{2}$ were investigated via the SEM images obtained at a scale of $2 \mu \mathrm{m}$ (Fig. 1A). The surface of MCM-41- $\mathrm{NH}_{2}$ consists of several spherical-shaped grains accumulating with each other. The diameter of these grains is in the nanoscale range, and the diameter of the largest particle is clearly less than $0.1 \mathrm{~nm}$. Furthermore, $\mathrm{MCM}-41-\mathrm{NH}_{2}$ comprises a large number of small cavities. Because of both the spherical grains and cavities, $\mathrm{MCM}-41-\mathrm{NH}_{2}$ will exhibit excellent properties, such as large surface area and high porosity, in adsorption systems. Notably, large surface area and high porosity indicate a large number of adsorption (active) sites for pollutant 
molecules (Heidari et al., 2009). Thus, it can be concluded that $\mathrm{MCM}-41-\mathrm{NH}_{2}$ can serve as an appropriate adsorbent for the adsorption of CIP molecules from contaminated solution.

Figure 1B presents the results of the BET analysis. The specific surface area, mean pore diameter, and volume of $\mathrm{MCM}-41-\mathrm{NH}_{2}$ are $524 \mathrm{~m}^{2} / \mathrm{g}, 3.1 \mathrm{~nm}$, and $0.87 \mathrm{~cm}^{3} / \mathrm{g}$, respectively. A relatively narrow size distribution of MCM-41 with a noticeable peak was observed, which was related to the pores with $2-4 \mathrm{~nm}$ diameter. The isotherm shown in Fig. 1B is a typical type-IV isotherm with a well-defined hysteresis loop, which reveals the presence of mesopores (Yokoi et al., 2012).

XRD patterns of $\mathrm{MCM}-41$ and $\mathrm{MCM}-41-\mathrm{NH}_{2}$ are shown in Fig. 1C. The XRD pattern of MCM-41- $\mathrm{NH}_{2}$ exhibited a strong high-intensity peak at $2 \theta=1.8^{\circ}(100)$. Furthermore, two lowintensity peaks were observed at $2 \theta=3.2^{\circ}(110)$ and $3.9^{\circ}(200)$. These three peaks were not noticed in the XRD pattern of MCM-41. In fact, the presence of these peaks in the XRD pattern of $\mathrm{MCM}-41-\mathrm{NH}_{2}$ indicates the formation of cavities with a regular hexagonal structure during amino-functionalization (Kirik et al., 2014). Numerous studies have reported that the formation of these cavities in an adsorbent may play an important role in the adsorption process as these cavities lead to a considerable number of active sites for the adsorption of pollutant molecules (Khodadadi et al., 2019, Mohammed et al., 2020b, Alwared et al., 2021).

Figure 1D shows the thermogravimetric (TG) curves of MCM-41- $\mathrm{NH}_{2}$ and $\mathrm{MCM}-41$. The TG curve of MCM-41 demonstrated three steps of weight loss. Moreover, the TG curve of MCM41- $\mathrm{NH}_{2}$ indicated a gradual weight loss of $\mathrm{MCM}-41-\mathrm{NH}_{2}$ up to $800{ }^{\circ} \mathrm{C}$ and three steps of weight loss. In the first step, the weight loss was approximately $3.0 \%$, which was attributed to the desorption of physisorbed water retained in the pores. In the second step, the weight loss was approximately $5.0 \%$, which was primarily owing to the oxidative destruction of the organic 
functional groups. The weight loss in the final step, which was approximately $2.0 \%$, was ascribed to the loss of water formed by the condensation of the $\mathrm{Si}-\mathrm{OH}$ groups.

FTIR spectra of MCM-41 and MCM-41- $\mathrm{NH}_{2}$ in the wavenumber range of $400-4000 \mathrm{~cm}^{-1}$ are shown in Fig. 1E. The broad band detected at $3540 \mathrm{~cm}^{-1}$ in the FTIR spectrum of MCM-41 is related to the reaction of the $\mathrm{Si}-\mathrm{OH}$ groups with the absorbed water molecules and destruction of the active sites (Lam et al., 2006). In addition, the bands at 1099, 800, and $492 \mathrm{~cm}^{-1}$ are attributed to the vibrations, asymmetric stretching, and bending vibration of $\mathrm{Si}-\mathrm{O}-\mathrm{Si}$, respectively. In the FTIR spectrum of $\mathrm{MCM}-41-\mathrm{NH}_{2}$, the new broad bands observed in the range of 1465-1642 $\mathrm{cm}^{-1}$ are attributed to the bending vibration of the $\mathrm{N}-\mathrm{H}$ group. The appearance of these bands confirmed the successful interaction of $\mathrm{NH}_{2}$ with $\mathrm{MCM}-41$. Furthermore, the bands of $\mathrm{N}-\mathrm{H}$ stretching and $\mathrm{C}-\mathrm{N}$ stretching at $3300-3750$ and $1000-1100 \mathrm{~cm}^{-1}$, respectively, overlapped with the broad band of the $\mathrm{Si}-\mathrm{OH}$ group (Martin et al., 2001). By comparing the FTIR spectra acquired before and after the functionalization of MCM-41, it can be deduced that these two spectra are harmonic with no substantial differences. This implies that the amination of the pore walls of MCM-41 did not significantly change or damage the structure of MCM-41. Instead, the structure of MCM-41 was improved after amination, with the emergence of new active $\mathrm{N}-\mathrm{H}$ groups.

$\mathrm{pH}_{\mathrm{pzc}}$ of $\mathrm{MCM}-41-\mathrm{NH}_{2}$ was found to be 7.3 (Fig. 1F). The analysis of $\mathrm{pH}_{\mathrm{pzc}}$ is very important to study the effects of solution $\mathrm{pH}$ on the adsorption process. Based on the results of this analysis, at $\mathrm{pH} 7.3$, the net charge on the $\mathrm{MCM}-41-\mathrm{NH}_{2}$ surface was zero. In addition, the surface of $\mathrm{MCM}-41-\mathrm{NH}_{2}$ had a negative charge at $\mathrm{pH}$ greater than 7.3 and vice-versa. 

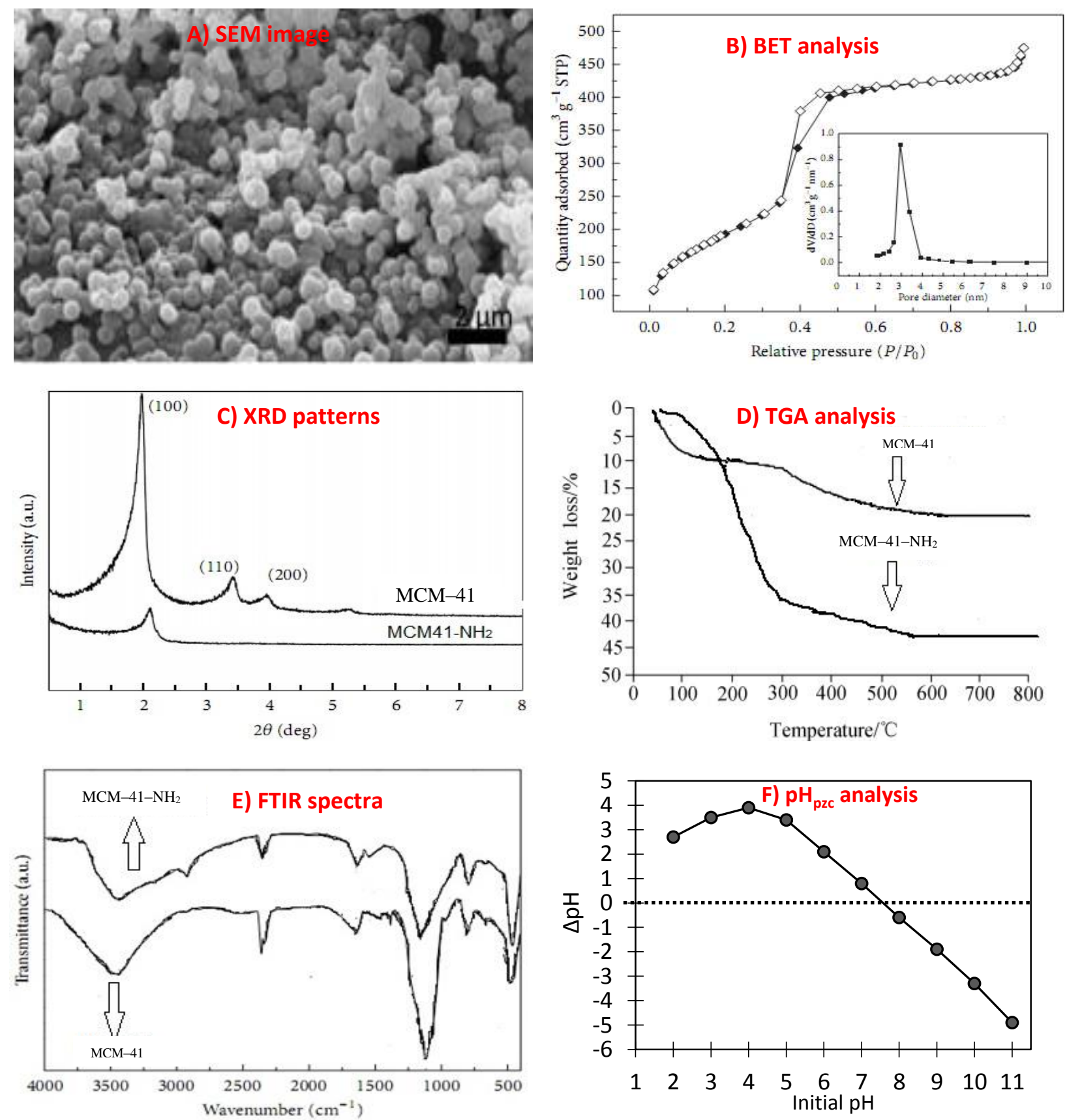

Figure 1. Characterization of $\mathrm{MCM}-41-\mathrm{NH}_{2}$ and $\mathrm{MCM}-41$ samples

\subsection{Effects of physicochemical parameters}

Many studies have demonstrated that the pollutant $R E$ and $q_{t}$ of an adsorbent are significantly affected by various physicochemical parameters. Generally, solution $\mathrm{pH}$ and temperature have a 
considerable impact on the pollutant $R E(\%)$ of adsorbents as the type of surface charge of the adsorbent and the dissolution rate of the pollutant molecules mainly depend on these two parameters (Nasseh et al., 2021, Khodadadi et al., 2019). From an economic perspective and for designing large-scale treatment processes, determination of optimum adsorbent dose for the removal of pollutants is important. In addition, the most important analyses in the isotherm study depend on the relationship between the $q_{t}$ of the adsorbent for pollutant at a constant temperature. Investigation of the effects of pollutant concentration on $t$ is essential for the kinetic study (Al-Musawi et al., 2018). Furthermore, numerous studies have reported that the effect of shaking speed on the adsorption of pollutants should be considered (Kuśmierek and Świątkowski, 2015, Abdelkareem et al., 2019). In the thermodynamic study, analyzing the effect of temperature on the adsorption process is crucial (Rostamian and Behnejad, 2016, Mahvi et al., 2018). In the present study, the effects of the abovementioned physicochemical parameters on the CIP adsorption process were studied (Fig. 2).

\subsubsection{Effects of $\mathrm{pH}$}

Results of the effect of $\mathrm{pH}$ on the CIP $R E$ of MCM-41- $\mathrm{NH}_{2}$ are shown in Fig. 2a (conditions of this experiment were as follows: $\mathrm{pH}=2-11 ; M / V=0.8 \mathrm{~g} / \mathrm{L} ; \mathrm{CIP}$ concentration $=10 \mathrm{mg} / \mathrm{L} ; t=$ $60 \mathrm{~min}$; shaking speed $=200 \mathrm{rpm}$; and temperature $=25 \pm 2{ }^{\circ} \mathrm{C}$ ). The CIP $R E$ increased with an increase in $\mathrm{pH}$ from 3 to 7, and the maximum CIP $R E$ achieved herein was 97.48\%. In addition, the CIP RE of MCM-41- $\mathrm{NH}_{2}$ decreased when $\mathrm{pH}$ was greater than 7. To explain these results, both the $\mathrm{pH}_{\mathrm{pzc}}$ of the adsorbent and the type of charges of the pollutant molecule in the studied $\mathrm{pH}$ range should be considered. Herein, the $\mathrm{pH}_{\mathrm{pzc}}$ of $\mathrm{MCM}-41-\mathrm{NH}_{2}$ is 7.3 (Figure 1F), which suggests that at a solution $\mathrm{pH} \leq 7.3$, the surface of $\mathrm{MCM}-41-\mathrm{NH}_{2}$ will have a positive charge and vice-versa. On other hand, at $\mathrm{pH} \leq 6.1$ ( $\mathrm{pKa} 1$ value of the CIP molecule), the surface of CIP 
will be positively charged due to the protonation of the amine functional groups on MCM-41 by surplus $\mathrm{H}^{+}$formed in the acidic $\mathrm{pH}$ medium (Amini et al., 2010). Thus, the repulsive forces occurring at $\mathrm{pH} \leq 6.1$ will hamper the adsorption of CIP molecules on MCM-41- $\mathrm{NH}_{2}$. The gradual increase in the repulsion rate with a decrease in the $\mathrm{pH}$ of the solution because of the increase in the amount of $\mathrm{H}^{+}$explains the decrease in the CIP $R E$ with a decrease in $\mathrm{pH}$, particularly to below 6 (Al-Musawi et al., 2018, Nasseh et al., 2020). In addition, the CIP $R E$ decreased at $\mathrm{pH}$ above 7 because at a $\mathrm{pH}$ greater than 8.7 ( $\mathrm{pKa} 2$ value of the CIP molecule), the CIP molecules exist as anionic species owing to the loss of protons from the carboxyl group ($\mathrm{COOH}$ ) of CIP (Table 1). Therefore, repulsion occurs between the negatively charged surfaces of MCM-41- $\mathrm{NH}_{2}$ and CIP molecules in the aqueous solution, specifically at $\mathrm{pH}$ above 8 .

In the $\mathrm{pH}$ range from 6.1 to 8.7 , deprotonation of $-\mathrm{COOH}$ results in the production of negatively charged CIP molecules (Peng et al., 2016). Furthermore, the amine group remains protonated (positively charged) (Parsa et al., 2016). Therefore, in this $\mathrm{pH}$ range, most of the CIP molecules in the aqueous solution have both positive and negative charges (zwitterion). Moreover, in this $\mathrm{pH}$ range, the surfaces of $\mathrm{MCM}-41-\mathrm{NH}_{2}$ are both positively and negatively charged. Under these conditions, the attraction between $\mathrm{MCM}-41-\mathrm{NH}_{2}$ and CIP molecules, and thus the adsorption of the CIP molecules on $\mathrm{MCM}-41-\mathrm{NH}_{2}$ are high because their surfaces have dissimilar charges. These results are consistent with those obtained in similar previously reported studies (Parsa et al., 2016, Mohammed et al., 2019). Based on these results, it can be inferred that the adsorption of CIP on MCM-41- $\mathrm{NH}_{2}$ will be optimum at neutral $\mathrm{pH}$. From the water and wastewater treatment and cost prespectives, a treatment that can be performed at neutral or near 
neutral $\mathrm{pH}$ is favorable because it normally does not require $\mathrm{pH}$ adjustment in advance (Mohammed et al., 2019, Khodadadi et al., 2019).

\subsubsection{Effects of $M / V$}

Results of the effect of $M / V$ on the CIP $R E$ of $M C M-41-\mathrm{NH}_{2}$ are shown in Fig. $2 \mathrm{~b}$ (conditions of this experiment were as follows: $\mathrm{pH}=7 ; M / V=0.1-1.4 \mathrm{~g} / \mathrm{L} ; \mathrm{CIP}$ concentration $=10 \mathrm{mg} / \mathrm{L} ; t$ $=60 \mathrm{~min}$; shaking speed $=200 \mathrm{rpm}$; and temperature $=25 \pm 2{ }^{\circ} \mathrm{C}$ ). When $M / V$ was increased from $0.1 \mathrm{~g} / \mathrm{L}$ to $0.8 \mathrm{~g} / \mathrm{L}$, the CIP $R E$ increased from $49.60 \%$ to $97.09 \%$. This is because with an increase in $M / V$ at a fixed CIP concentration, the number of active sites also increases with respect to the concentration of CIP in the aqueous solution (Zhang et al., 2011, Zha et al., 2013). However, when $M / V$ was further increased above $0.8 \mathrm{~g} / \mathrm{L}$, the CIP $R E$ did not significantly vary. This is because at low pollutant concentrations, the adsorption of pollutant molecules is more difficult (Li et al., 2017, Davis et al., 2003). Another reason that has been highlighted in the literature is that the agglomeration of some adsorbent particles at high doses reduces the availability of active sites for the pollutant molecules (Khodadadi et al., 2019). Based on these facts, $0.8 \mathrm{~g}$ was considered as the optimum $M / V$ for the treatment of $1 \mathrm{~L}$ CIP solution with a CIP concentration of $10 \mathrm{mg} / \mathrm{L}$.

\subsubsection{Effects of $C_{0}$}

Effects of $C_{0}$ on the CIP $R E$ of MCM-41- $\mathrm{NH}_{2}$ were examined as a function of $t$ (Figure 2c) as this information is important to accomplish the kinetic study. This experiment was perfomed under the following conditions: $\mathrm{pH}=7 ; M / V=0.8 \mathrm{~g} / \mathrm{L} ; \mathrm{CIP}$ concentration $=10-100 \mathrm{mg} / \mathrm{L}$; shaking speed $=200 \mathrm{rpm} ; t=0-10 \mathrm{~min} ;$ and temperature $=25 \pm 2{ }^{\circ} \mathrm{C}$. Clearly, the $\mathrm{CIP} R E$ increased from $82.25 \%$ to $99.25 \%$ when $C_{0}$ was decreased from $100 \mathrm{mg} / \mathrm{L}$ to $10 \mathrm{mg} / \mathrm{L}$. In 
addition, the plotted curves of the CIP $R E$ of $\mathrm{MCM}-41-\mathrm{NH}_{2}$ presented similar profiles at all analyzed $C_{0}$ values. This is because in this experiment, $M / V$ in the aqueous solution was fixed, and therefore, there were a limited number of active sites. With an increase in $C_{0}$, competition between CIP molecules to occupy the available active sites increased (Danalığlu et al., 2017, Kakavandi et al., 2014). Figure 1C also shows that the rate of adsorption of CIP on MCM-41$\mathrm{NH}_{2}$ was high as the removal of more than $60 \%$ CIP was achieved in the first 30 min of adsorption at all CIP concentrations investigated herein. Furthermore, equilibrium adsorption occurred after $60 \mathrm{~min}$ of adsorption. The ascending limb of the plotted curves was very steep, and after $40 \mathrm{~min}$ of adsorption, the slopes of these curves gradually became mild (Figure 1C). This was because of the availability of a large number of active sites at the beginning of adsorption. In addition, this indicated rapid transport of the CIP molecules from the aqueous solution to MCM-41- $\mathrm{NH}_{2}$ via adsorption (Zha et al., 2013). These results showed that it is possible to achieve a CIP $R E$ of up to $99 \%$ if adsorption is proceeded for $120 \mathrm{~min}$. Accordingly, 120 min can be concluded as the optimum $t$ for the adsorption of CIP on MCM-41- $\mathrm{NH}_{2}$ to ensure the achievement of full equilibrium status.

\subsubsection{Effect of shaking speed}

Shaking speed has a direct effect on the mixing degree and thus the rate of contact of pollutant molecules with adsorbent particles; therefore, the adsorption of pollutant molecules is highly dependent on this parameter. Figure $2 \mathrm{~d}$ shows the effect of the increase in shaking speed from 50 rpm to $200 \mathrm{rpm}$ on the CIP $R E$ of $\mathrm{MCM}-41-\mathrm{NH}_{2}$ under the following conditions: $\mathrm{pH}=7 ; M / V$ $=0.8 \mathrm{~g} / \mathrm{L} ;$ CIP concentration $=10 \mathrm{mg} / \mathrm{L} ; t=60 \mathrm{~min} ;$ shaking speed $=50-200 \mathrm{rpm} ;$ and temperature $=25 \pm 2{ }^{\circ} \mathrm{C}$ ). The increase in shaking speed improved the CIP $R E$ of MCM-41-NH because with an increase in the shaking speed, the mixing rate of adsorbent particles in the 
aqueous solution also increased; this enhanced the rate of collision and interaction between the pollutant molecules and adsorbent particles owing to the increase in the adsorption rate. In addition, with an increase in the mixing rate of adsorbent particles in the aqueous solution, the boundary layer on the solid particles reduced; therefore, the resistance of the thin layer around the adsorbent particles to mass transfer diminished (Balarak et al., 2017). Above the shaking speed of $200 \mathrm{rpm}$, the CIP RE remained stable; thus, based on these results, it can be concluded that $200 \mathrm{rpm}$ is the optimum shaking speed for the adsorption of CIP on MCM-41- $\mathrm{NH}_{2}$.
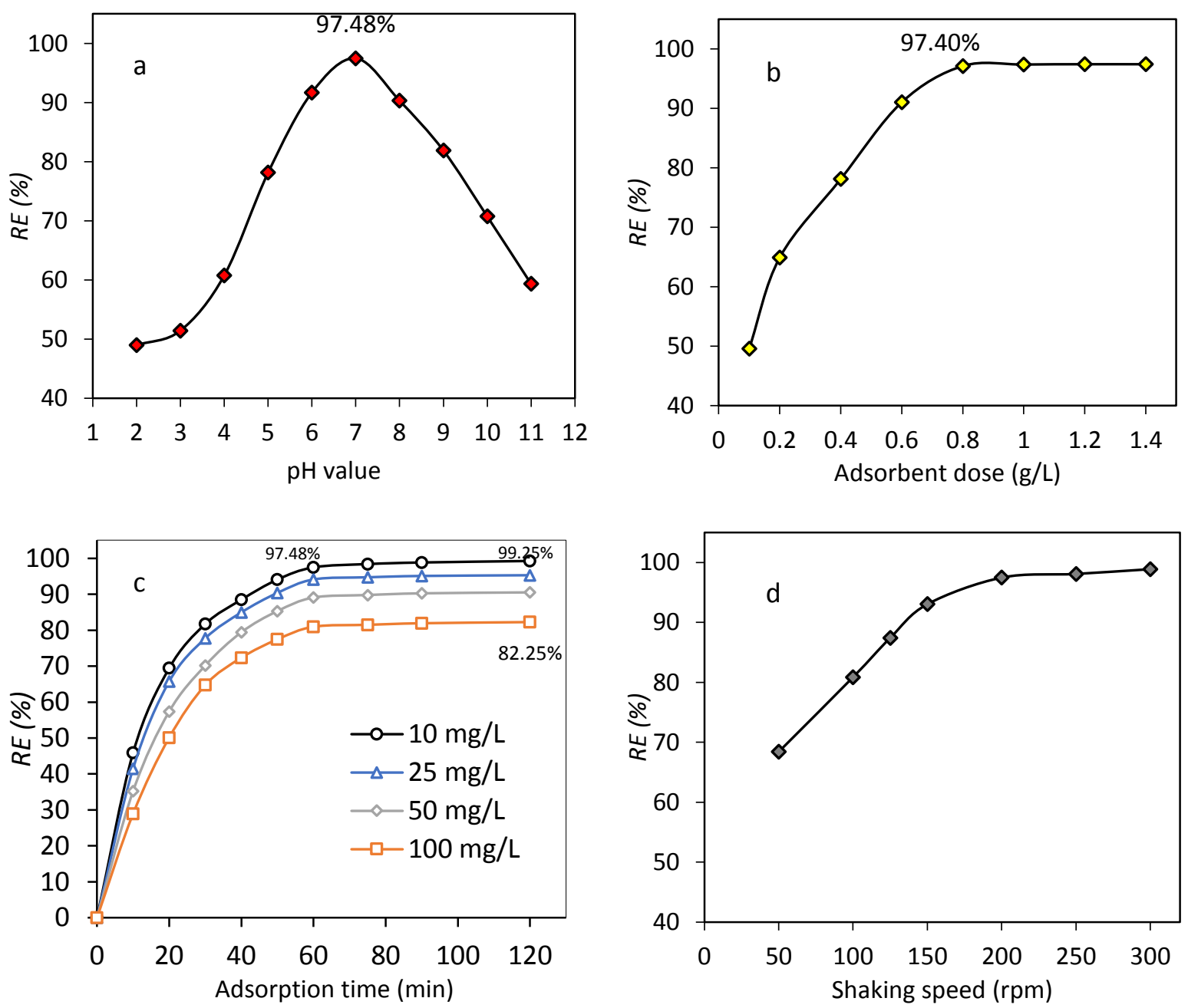

Figure 2. Effects of (a) solution $\mathrm{pH}$, (b) adsorbent dose, (c) initial ciprofloxacin concentration, and (d) shaking speed on the ciprofloxacin removal efficiency of $\mathrm{MCM}-41-\mathrm{NH}_{2}$ 


\subsection{Adsorption kinetics}

Kinetic analysis is essential to evaluate the practical applicability of an adsorbent as it is useful for understanding the mechanism and rate of adsorption (Brouers and Al-Musawi, 2020, AlMusawi et al., 2018). In addition, determination of a mathematical formula that can describe the kinetic reactions of an adsorbent-adsorbate system is necessary for the precise design of largescale treatment processes (Balarak et al., 2020). Therefore, the experimental data shown in Fig. 2c were first treated using Equation 1 and then analyzed in terms of pseudo-first-order (PFO) and pseudo-second-order (PSO) kinetic models. Equations 3 and 4 are the linear forms of the PFO and PSO models, respectively (Azizian, 2004, Ho, 2006). Furthermore, the data presented in Fig. 2c were modeled using the intraparticle diffusion model (Equation 5) (Zhang et al., 2011). In fact, the application of the intraparticle diffusion model is important as this model provides information about the role of intraparticle diffusion rate in controlling adsorption.

$\log \left(q_{e}-q_{t}\right)=\log q_{e}-\frac{K_{1}}{2.303} t$

$\frac{t}{q_{t}}=\frac{1}{K_{2} q_{e}^{2}}+\frac{t}{q_{e}}$

$q_{t}=K_{b} t^{0.5}+I$

where $K_{1}(1 / \mathrm{min})$ and $K_{2}(\mathrm{~g} / \mathrm{mg} \cdot \mathrm{min})$ are the PFO and PSO rate constants, respectively. Moreover, $K_{b}\left(\mathrm{mg} / \mathrm{g} \cdot \mathrm{min}^{0.5}\right)$ is the rate constant of the intraparticle diffusion model, and $I(\mathrm{mg} / \mathrm{g})$ is the intraparticle constant that provides information about the thickness of the boundary layer.

Results of the CIP kinetic analysis are listed in Table 2. Regarding the PFO and PSO models, the relevant parameters were determined based on the equations of the trend lines of the two plots shown in Fig. $3 \mathrm{a}$ and b, respectively. $K_{1}$ represents the slope of the trend line and is calculated 
from the plot of $\log \left(q_{e}-q_{t}\right)$ vs. $t$ points. Furthermore, $K_{2}$ is determined from the linear plot of $\frac{t}{q_{t}}$ vs. $t$ data. The fitting of each kinetic model with the kinetic data was estimated in accordance with the coefficient of determination $\left(R^{2}\right)$ values and the convergence between the calculated uptake $\left(q_{e}(\mathrm{cal})\right)$ and experimental uptake $\left(q_{e}(\exp )\right)$ (Table 3). Results showed that high regression levels were obtained for the fitting of the PSO model as compared to those for the fitting of the PFO model. Additionally, the values of $q_{e}(\mathrm{cal})$ of the PSO model were close to the $q_{e}(\exp )$ values. Therefore, the adsorption kinetics followed the PSO model, suggesting the chemisorption of CIP on MCM-41- $\mathrm{NH}_{2}$ (Al-Musawi et al., 2018, Khodadadi et al., 2019).

The analysis of the intraparticle diffusion model indicates that the adsorption of CIP comprises two phases (Fig. 3c). The first phase ending at $t^{0.5}<8 \min ^{0.5}$ represents the surface and intraparticle diffusion processes, and the second linear phase observed after $t^{0.5}>8 \min ^{0.5}$ denotes the equilibrium condition of the adsorption of CIP molecules on the porous active sites of MCM-41- $\mathrm{NH}_{2}$. The value of $K_{b}$ represents the slope of the linear plot equation of the first phase. Actually, results showed a low compatibility level of the experimental data with the intraparticle diffusion model (Table 2). Therefore, it can be concluded that the intraparticle diffusion process is not the only rate-controlling step, and during adsorption, the rate-controlling mechanism may change (Yu et al., 2016).

To examine the fraction of the adsorbent surface occupied by the CIP molecules, surface coverage analysis was conducted. In fact, an increase in surface coverage implies an increase in the pollutant $R E$ of the adsorbent. Surface coverage can be calculated using the following equation (Çalışkan and Göktürk, 2010):

Surface coverage $=\frac{C_{0}-C_{t}}{C_{0}+\left(\frac{K_{1}}{K_{2}}\right)}$ 
In the present study, the surface coverage of $\mathrm{MCM}-41-\mathrm{NH}_{2}$ due to the adsorption of CIP molecules was calculated at different $t$, and the results are shown in Fig. $3 \mathrm{~d}$ (conditions of this experiment were as follows: $\mathrm{pH}=7 ; M / V=0.8 \mathrm{~g} / \mathrm{L}$; CIP concentration $=100 \mathrm{mg} / \mathrm{L}$; shaking speed $=200 \mathrm{rpm} ; t=0-120 \mathrm{~min} ;$ and temperaure $\left.=25 \pm 2{ }^{\circ} \mathrm{C}\right)$. The surface coverage of MCM41- $\mathrm{NH}_{2}$ increased with an increase in $t$. This means that the surface of MCM-41- $\mathrm{NH}_{2}$ becomes progressively occupied by the CIP molecules with an increase in $t$. This finding is completely consistent with the results of the effect of $t$ on the CIP $R E$ of MCM-41-NH2. Furthermore, the maximum coverage of the MCM-41- $\mathrm{NH}_{2}$ surface by the CIP molecules was $82 \%$ of the total surface area.

Table 2. Results of the kinetic analysis of CIP adsorption on MCM-41- $\mathrm{NH}_{2}$

\begin{tabular}{|c|c|c|c|c|c|c|c|c|c|c|}
\hline \multirow[b]{2}{*}{$C_{0}$} & \multirow[b]{2}{*}{$q_{e}(\exp )$} & \multicolumn{3}{|c|}{ PFO model } & \multicolumn{3}{|c|}{ PSO model } & \multicolumn{3}{|c|}{$\begin{array}{l}\text { Intraparticle diffusion } \\
\text { model }\end{array}$} \\
\hline & & $q_{e}(c a l)$ & $K_{1}$ & $R^{2}$ & $q_{e}(c a l)$ & $K_{2}$ & $R^{2}$ & $K_{b}$ & $I$ & $R^{2}$ \\
\hline 10 & 12.42 & 13.58 & 0.085 & 0.89 & 13.88 & 0.0024 & 0.996 & 0.802 & 5.096 & 0.774 \\
\hline 25 & 29.71 & 42.65 & 0.071 & 0.884 & 34.48 & 0.0047 & 0.994 & 2.019 & 11.45 & 0.772 \\
\hline 50 & 56.55 & 86.69 & 0.069 & 0.886 & 66.61 & 0.0059 & 0.995 & 4.284 & 17.56 & 0.791 \\
\hline 100 & 102.80 & 148.20 & 0.066 & 0.885 & 125.00 & 0.0075 & 0.997 & 8.173 & 28.60 & 0.775 \\
\hline
\end{tabular}



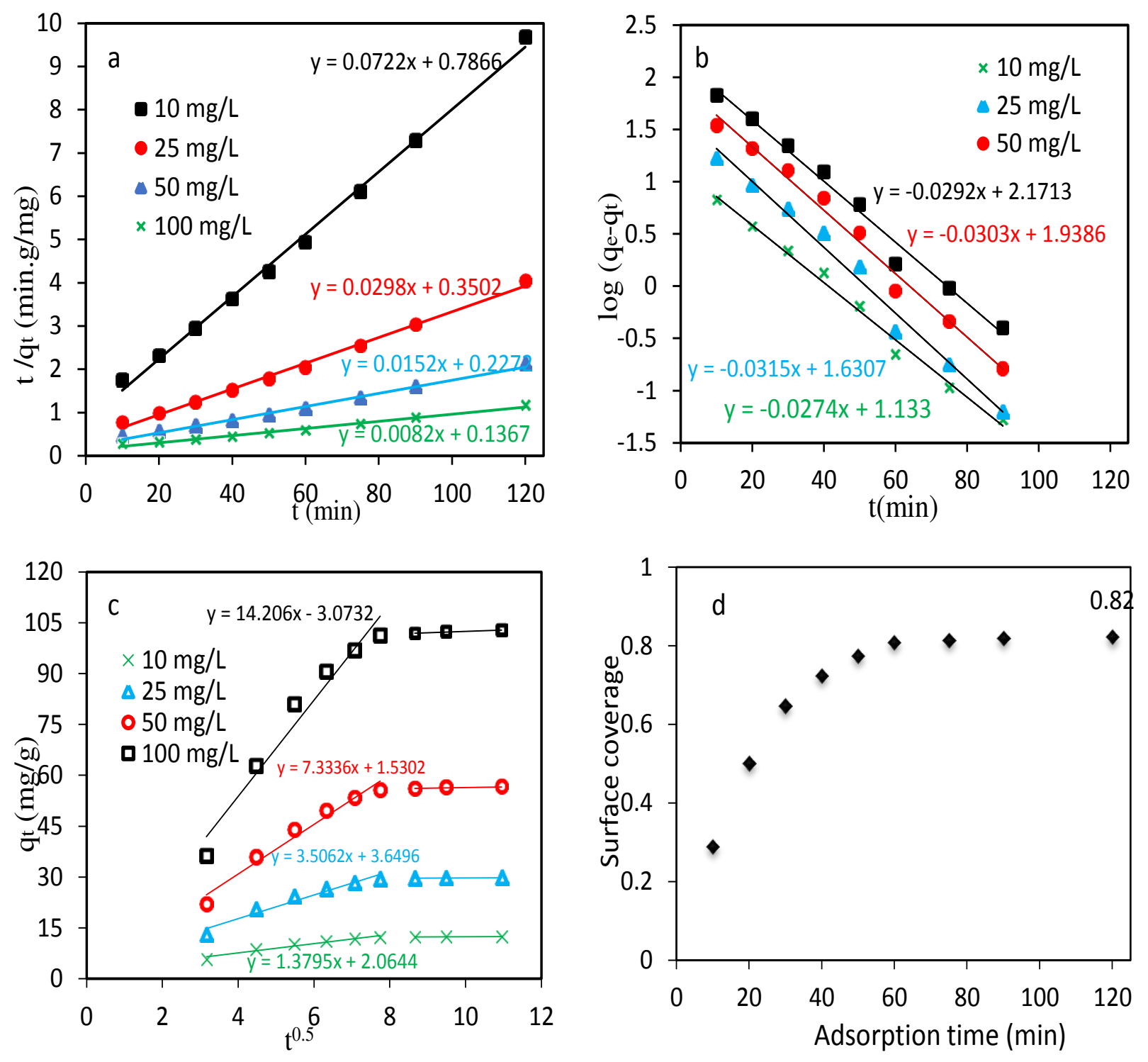

Figure 3. Kinetic data analysis of CIP adsorption on $M C M-41-\mathrm{NH}_{2}$ using (a) pseudo-first-order,

(b) pseudo-second-order, and (c) intraparticle diffusion models, and (d) surface coverage of MCM-41-NH $\mathrm{N}_{2}$ as a function of adsorption time

\subsection{Adsorption isotherm}

Modeling the isotherm data with isotherm models is one of the basic requirements for the efficient design of adsorption treatment systems and determination of $q_{m}$ of an adsorbent for the 
target pollutant (Brouers and Al-Musawi, 2020). In this study, four isotherm models were applied, and their compatibility with the isotherm data was analyzed: Langmuir, Freundlich, Temkin, and Dubinin-Radushkevich isotherm (D-R) models. The Langmuir model (Equation 7) assumes that in adsorption systems, each pollutant molecule interacts with one active site located on the adsorbent surface (monolayer adsorption), and all the active sites located on the adsorbent are homogeneous and have equal binding energies. Thus, in the Langmuir model, adsorption is characterized as monolayer and homogeneous (Brouers and Al-Musawi, 2020, Khodadadi et al., 2019, Alhassani et al., 2020).

$\frac{C_{e}}{q_{e}}=\frac{1}{q_{m} K_{L}}+\frac{C_{e}}{q_{m}}$

where $q_{m}(\mathrm{mg} / \mathrm{g})$ is a very important parameter in the adsorption studies, denoting the maximum $q_{t}$ of the adsorbent for the target pollutant, and $K_{L}(\mathrm{~L} / \mathrm{mg})$ is an equilibrium constant reflecting the affinity level of the active sites of the adsorbent.

In addition, the characteristics of adsorption using the Langmuir model can be defined based on the dimensionless separation factor $\left(R_{L}\right)$ (Equation 8). Based on the $R_{L}$ value, the favorable adsorption case can only be detected at $0<R_{L}<1$.

$R_{L}=\frac{1}{\left(1+K_{L} C_{0}\right)}$

Freundlich equation (Equation 9) is an empirical isotherm model generally used to express multilayer and heterogeneous adsorption systems (Erşan et al., 2013, Al-Jubouri et al., 2018). Moreover, it supposes that the total adsorption energy exponentially decreases during adsorption.

$$
\ln q_{e}=\frac{1}{n} \ln C_{e}+\ln K_{F}
$$


where $K_{F}$ is the Freundlich constant, indicative of the binding energy $(\mathrm{mg} / \mathrm{g})(\mathrm{L} / \mathrm{mg})^{1 / \mathrm{n}}$, and $\frac{1}{n}$ is the heterogeneity parameter.

Temkin equation (Equation 10) is a complex isotherm model used to describe the indirect adsorption process of pollutant molecules on active sites (Zhao et al., 2014). Furthermore, this model hypothesizes that adsorption energy linearly decreases during the occupation of the adsorption center of an adsorbent (Gao et al., 2012). In general, this model is highly applicable to describe the chemical adsorption type (Nasseh et al., 2021).

$q_{e}=B \ln K_{T}+B \ln C_{e}$,

where $K_{T}$ and $B=\frac{R T}{b}$ are constants that provide information about the heat of sorption $(\mathrm{J} / \mathrm{mol}), b$ is the Temkin isotherm constant $(\mathrm{L} / \mathrm{g}), R$ is the ideal gas constant $(8.314 \mathrm{~J} /(\mathrm{mol} \cdot \mathrm{K}))$, and $T$ is the thermodynamic absolute temperature $(\mathrm{K})$.

For systems where the adsorption curve depends on the porous surface of the adsorbent, the D-R model (Equation 11) is appropriate. Using the D-R model, the nature (physical or chemical) of the adsorption mechanism can be determined (Al-Jubouri and Holmes, 2020, Guler and Sarioglu, 2014).

$\ln q_{e}=\ln q_{m}+\beta \varepsilon^{2}$

where $\beta\left(\mathrm{mol}^{2} / \mathrm{kJ}^{2}\right)$ is the activity coefficient constant associated with the mean free sorption energy, which is denoted by $E=\frac{1}{\sqrt{-2 \beta}}(\mathrm{kJ} / \mathrm{mol})$, and $\varepsilon=R T \ln \left(1+\frac{1}{C_{e}}\right)$ is the Polanyi potential $(\mathrm{kJ} / \mathrm{mol})$.

Constants of each isotherm model applied in this study and $R^{2}$ values are listed in Table 3 . The highest $R^{2}$ values were found for the Langmuir model; thus, the adsorption of CIP on MCM-41- 
$\mathrm{NH}_{2}$ is consistent with the Langmuir model. These results indicate that the CIP molecules are adsorbed on a monolayer of the homogeneous active sites of $\mathrm{MCM}-41-\mathrm{NH}_{2}$. The maximum uptake of CIP by MCM-41- $\mathrm{NH}_{2}$ based on the best fit model was $164.3 \mathrm{mg} / \mathrm{g}$ at $328 \mathrm{~K}$. Based on the determined $R_{L}$ values of the Langmuir model, which are between zero and one, it can be concluded that the adsorption of CIP on MCM-41- $\mathrm{NH}_{2}$ is favorable. In addition, as the value of the Freundlich parameter $n$ is greater than one at all temperatures considered herein, the abovementioned adsorption process is suitable. Moreover, the $K_{T}$ values of the Temkin isotherm increased with an increase in temperature, indicating that adsorption is superior at high temperatures and the adsorption process is endothermic. According to the $E$ value of the D-R model, which is less than $8 \mathrm{~kJ} / \mathrm{mol}$, the adsorption of CIP on MCM-41- $\mathrm{NH}_{2}$ is physical (To et al., 2017, Nguyen and Do, 2001, Zhao et al., 2014). 
Table 3. Freundlich, Langmuir, Dubinin-Radushkevich, and Temkin isotherm parameters for the adsorption of CIP on MCM-41- $\mathrm{NH}_{2}$ at different temperatures (conditions of this experiment were as follows: $\mathrm{pH}=7 ; \mathrm{MCM}-41-\mathrm{NH}_{2}$ dose $=0.1-1.4 \mathrm{~g} / \mathrm{L} ; \mathrm{CIP}$ concentration $=10 \mathrm{mg} / \mathrm{L}$; adsorption time $=120 \mathrm{~min} ;$ and shaking speed $=200 \mathrm{rpm})$

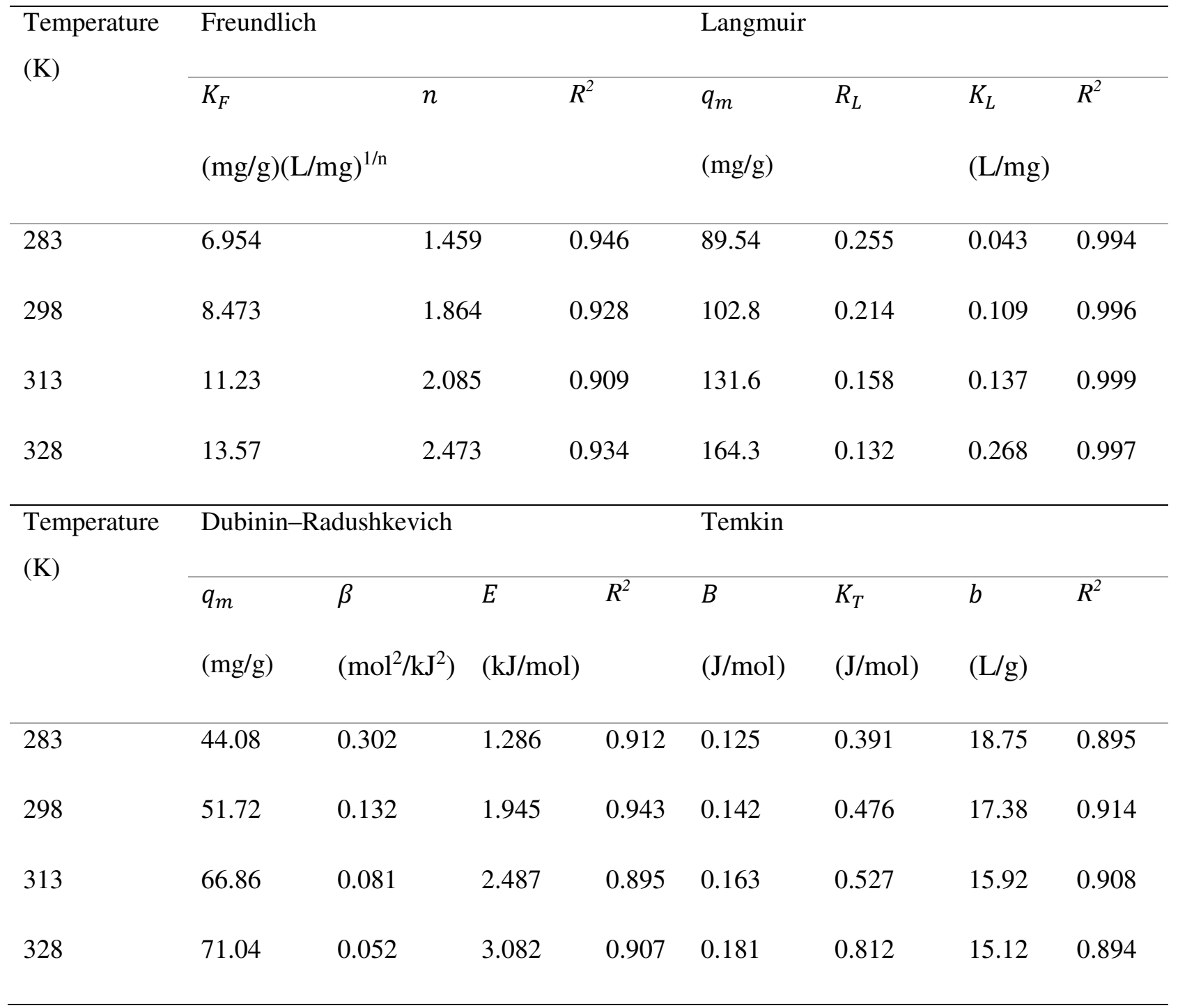

\subsection{Thermodynamic studies}

To investigate the effect of temperature on the mechanism of CIP adsorption on MCM-41- $\mathrm{NH}_{2}$, thermodynamic parameters, including enthalpy $\left(\Delta H^{o}\right)(\mathrm{kJ} / \mathrm{mol})$, entropy $\left(\Delta S^{o}\right)(\mathrm{kJ} / \mathrm{mol} \cdot \mathrm{K})$, and Gibbs free energy $\left(\Delta G^{o}\right)(\mathrm{kJ} / \mathrm{mol})$, were determined according to $q_{e}$ at different temperatures 
(283, 298, 313, and $328 \mathrm{~K})$. These three parameters were evaluated using Equations 12-15) (Azarpira and Balarak, 2016, Balarak and Azarpira, 2016).

$\Delta G^{o}=-R T\left(\ln K_{o}\right)$

$K_{o}=\frac{q_{e}}{C_{e}}$,

$\ln K_{o}=\frac{\Delta S^{o}}{R}-\frac{\Delta H^{o}}{R T}$

$\Delta G^{o}=\Delta H^{o}-T \Delta S^{o}$,

where $K_{o}(\mathrm{~L} / \mathrm{mg})$ is the equilibrium constant, $R$ is the ideal gas constant $(8.314 \mathrm{~J} /(\mathrm{mol} \cdot \mathrm{K}))$, and $T$ is the thermodynamic absolute temperature $(\mathrm{K})$. Note that $\Delta H^{o}$ and $\Delta S^{o}$ can be directly calculated from the linear plot of $\ln K_{o}$ vs. $1 / T$, and the slope and intercept with $y$-axis of the obtained trend line equation represent $\left(-\Delta H^{o} / R\right)$ and $\left(\Delta S^{o} / R\right)$, respectively. Thereafter, $\Delta G^{o}$ can be calculated using Equation 15.

Results of the thermodynamic analysis are presented in Table 4. Positive $\Delta H^{o}$ indicates that the adsorption of CIP on MCM-41- $\mathrm{NH}_{2}$ is endothermic, which is the reason for the formation of strong chemical bonds between the CIP molecules and MCM-41- $\mathrm{NH}_{2}$ surface. Moreover, positive $\Delta S$ implies the binding of $\mathrm{MCM}-41-\mathrm{NH}_{2}$ and the CIP molecules and the enhancement of the CIP $R E$ with an increase in temperature in the solid-liquid common phase during adsorption; furthermore, the values of $\Delta G^{o}$ suggest that the adsorption of CIP on MCM-41- $\mathrm{NH}_{2}$ is a spontaneous reaction (Liu et al., 2011). The increase in the negative values of $\Delta G^{o}$ with an increase in temperature may be because of the dehydration of both $\mathrm{MCM}-41-\mathrm{NH}_{2}$ and CIP, which simplifies the reaction between them and ultimately makes the adsorption of CIP on MCM-41- $\mathrm{NH}_{2}$ more favorable at high temperatures. 
Table 4. Thermodynamic parameters for the adsorption of CIP on MCM-41- $\mathrm{NH}_{2}$ (conditions of this experiment were as follows: $\mathrm{pH}=7 ; \mathrm{MCM}-41-\mathrm{NH}_{2}$ dose $=0.8 \mathrm{~g} / \mathrm{L} ; \mathrm{CIP}$ concentration $=10$ $\mathrm{mg} / \mathrm{L}$; adsorption time $=120 \mathrm{~min}$; and shaking speed $=200 \mathrm{rpm}$ )

\begin{tabular}{llll}
\hline Temperature $(\mathrm{K})$ & $\Delta G^{o}(\mathrm{~kJ} / \mathrm{mol})$ & $\Delta H^{o}(\mathrm{~kJ} / \mathrm{mol})$ & $\Delta S^{o}(\mathrm{~kJ} / \mathrm{mol} \cdot \mathrm{K})$ \\
\hline 283 & -2.68 & 53.24 & 0.194 \\
298 & -4.13 & & \\
313 & -6.33 & & \\
328 & -11.96 & & \\
\hline
\end{tabular}

\subsection{Regeneration and recycling analysis}

In the field of water and wastewater treatment using adsorption systems, one of the most important economic parameters is the reusability of the employed adsorbent (Huang et al., 2014). Therefore, in the present study, the recyclability of $\mathrm{MCM}-41-\mathrm{NH}_{2}$ was examined for eight consecutive CIP adsorption-desorption cycles under the following optimal conditions: $\mathrm{pH}=7$; $M / V=0.8 \mathrm{~g} / \mathrm{L} ;$ CIP concentration $=10 \mathrm{mg} / \mathrm{L} ; t=120 \mathrm{~min} ;$ shaking speed $=200 \mathrm{rpm} ;$ and temperature $=25 \pm 2{ }^{\circ} \mathrm{C}$. At the end of each CIP adsorption cycle, MCM-41- $\mathrm{NH}_{2}$ was separated from the aqueous solution via centrifugation. Then, it was rinsed with ethanol and deionized water to desorb the adsorbed CIP molecules, dried overnight in a vacuum oven at $75^{\circ} \mathrm{C}$, and then reused in the next adsorption cycle. The results of this experiment are presented in Fig. 4, revealing that MCM-41- $\mathrm{NH}_{2}$ used for CIP adsorption can be recycled eight times for the same purpose. Figure 4 also demonstrates that the CIP $R E$ of $\mathrm{MCM}-41-\mathrm{NH}_{2}$ reduced by only $9 \%$ from the $1^{\text {st }}$ to the $8^{\text {th }}$ adsorption cycle. This reduction may be because of the loss of the adsorption 
ability of MCM-41- $\mathrm{NH}_{2}$ due to filtration, centrifugation, and washing. Based on these results, it can be concluded that MCM-41- $\mathrm{NH}_{2}$ has high reusability in the CIP adsorption process.

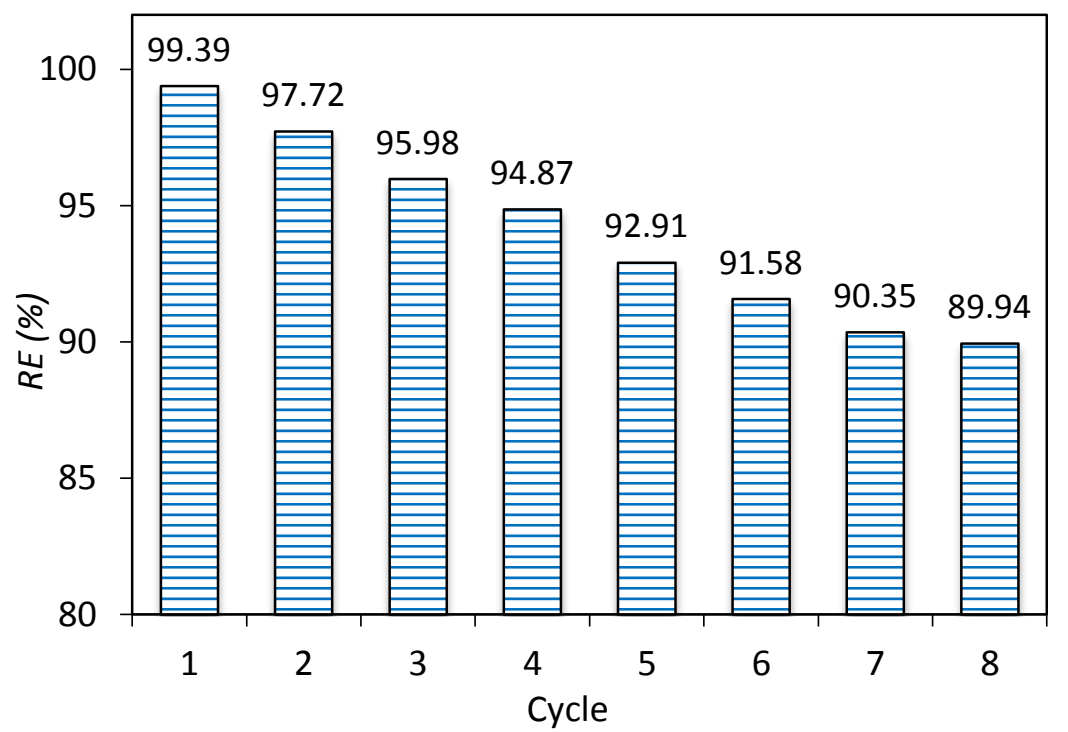

Figure 4. Regeneration and recycling analysis of $\mathrm{MCM}-41-\mathrm{NH}_{2}$ for the removal of CIP from aqueous solutions

\subsection{Comparison between the $q_{m}$ values of $\mathrm{MCM}-41-\mathrm{NH}_{2}$ and other previously reported adsorbents}

Table 5 presents the theoretical $q_{m}$ (determined from the Langmuir isotherm model) of MCM41- $\mathrm{NH}_{2}$ and other previously reported adsorbents used for CIP adsorption. Based on the $q_{m}$ values, it can be inferred that MCM-41- $\mathrm{NH}_{2}$ is a superior adsorbent for the removal of CIP molecules from aqueous solutions. 
Table 5. Comparison between the maximum adsorption capacities $\left(q_{m}\right)$ of $\mathrm{MCM}-41-\mathrm{NH}_{2}$ and other adsorbents used for CIP removal

\begin{tabular}{lll}
\hline Adsorbent & $\boldsymbol{q}_{\boldsymbol{m}}(\mathbf{m g} / \mathbf{g})$ & Reference \\
\hline $\mathrm{MCM}-41-\mathrm{NH}_{2}$ & 164.3 & This study \\
\hline $\begin{array}{l}\text { Powdered activated carbon magnetized by } \\
\mathrm{Fe}_{3} \mathrm{O}_{4} \text { nanoparticles }\end{array}$ & 109.83 & (Al-Musawi et al., 2021) \\
$\begin{array}{l}\text { Zinc oxide nanoparticle-coated pistachio shell } \\
\text { powder }\end{array}$ & 92.45 & (Mohammed et al., 2020a) \\
$\begin{array}{l}\text { Magnetic activated carbon/chitosan } \\
\text { Hazelnut (Corylus avellane) activated carbon }\end{array}$ & 73.64 & (Balarak et al., 2016) \\
Groundnut (Arachis hypogaea) shell powder & 8.86 & (Dhiman and Sharma, 2019) \\
ZnO nanoparticles & 8.30 & (Dhiman and Sharma, 2019) \\
MgO nanoparticles & 3.46 & (Khoshnamvand et al., 2017)
\end{tabular}

\section{Conclusion}

In this study, MCM-41- $\mathrm{NH}_{2}$ was prepared and used as an adsorbent to eliminate CIP from contaminated solutions. Characterization analyses reveal that $\mathrm{MCM}-41-\mathrm{NH}_{2}$ possesses unique properties and a high potential as an efficient adsorbent. In addition, these analyses showed that several characterization parameters, such as surface morphology, functional groups, and thermal stability, of the original MCM-41 material were improved after its modification via amination. According to the results of the Langmuir model, which fitted best to the experimental data, the $q_{m}$ of $\mathrm{MCM}-41-\mathrm{NH}_{2}$ for $\mathrm{CIP}$ was $164.3 \mathrm{mg} / \mathrm{g}$ at $328 \mathrm{~K}$. Furthermore, the kinetic study demonstrated that the experimental kinetic data at different CIP concentrations followed the PSO 
model, and intraparticle diffusion was not the only process controlling the adsorption of CIP on MCM-41- $\mathrm{NH}_{2}$. Moreover, the optimum environmental conditions for achieving the maximum CIP $R E(99.25 \%)$ were as follows: $\mathrm{pH}=7 ; M / V=0.8 \mathrm{~g} / \mathrm{L} ; \mathrm{CIP}$ concentration $=10 \mathrm{mg} / \mathrm{L} ; t=120$ min; and shaking speed $=200 \mathrm{rpm}$. Thus, $\mathrm{MCM}-41-\mathrm{NH}_{2}$ prepared herein is a highly efficient adsorbent for the adsorption of CIP. In addition, $\mathrm{MCM}-41-\mathrm{NH}_{2}$ can be reused eight times with only a $9 \%$ reduction in its adsorption capacity.

\section{Acknowledgements}

Authors acknowledge Zahedan University of Medical Sciences for providing financial support to this study.

\section{Declaration of competing interest}

There are no conflicts of interest to declare.

\section{References}

Abdelkareem, H., Alwared, A., Al-Musawi, T. J. \& Brouers, F. 2019. A Comparative Study for the Identification of Superior Biomass Facilitating Biosorption of Copper and Lead Ions: A Single Alga or a Mixture of Algae. International Journal of Environmental Research, 13, 533-546.

Al-Jubouri, S. M., De Haro-Del Rio, D. A., Alfutimie, A., Curry, N. A. \& Holmes, S. M. 2018. Understanding the seeding mechanism of hierarchically porous zeolite/carbon composites. Microporous and Mesoporous Materials, 268, 109-116.

Al-Jubouri, S. M. \& Holmes, S. M. 2020. Immobilization of cobalt ions using hierarchically porous 4A zeolite-based carbon composites: Ion-exchange and solidification. Journal of Water Process Engineering, 33, 101059.

Al-Musawi, T. J., Brouers, F., Zarrabi, M. \& Noroozi, R. 2018. What can the use of well-defined statistical functions of pollutants sorption kinetics teach us? A case study of cyanide sorption onto LTA zeolite nanoparticles. Environmental Technology \& Innovation, 10, 46-54.

Al-Musawi, T. J., Mahvi, A. H., Khatibi, A. D. \& Balarak, D. 2021. Effective adsorption of ciprofloxacin antibiotic using powdered activated carbon magnetized by iron(III) oxide magnetic nanoparticles. Journal of Porous Materials.

Alhassani, M. H., Al-Jubouri, S. M. \& Al-Jendeel, H. A. 2020. Stabilization of phenol trapped by agricultural waste: a study of the influence of ambient temperature on the adsorbed phenol. Desalination And Water Treatment, 187, 266-276.

Alwared, A. I., Al-Musawi, T. J., Muhaisn, L. F. \& Mohammed, A. A. 2021. The biosorption of reactive red dye onto orange peel waste: a study on the isotherm and kinetic processes and sensitivity analysis using the artificial neural network approach. Environmental Science and Pollution Research, 28, 2848-2859. 
Amini, M., Khanavi, M. \& Shafiee, A. 2010. Simple High-Performance Liquid Chromatographic Method for Determination of Ciprofloxacin in Human Plasma. Iranian Journal of Pharmaceutical Research, Volume 3, 99-101.

Azarpira, H. \& Balarak, D. 2016. Rice husk as a biosorbent for antibiotic metronidazole removal: Isotherm studies and model validation. International Journal of ChemTech Research, 9, 566-573.

Azizian, S. 2004. Kinetic models of sorption: a theoretical analysis. Journal of colloid and Interface Science, 276, 47-52.

Balarak, D., Al-Musawi, T. J., Mohammed, I. A. \& Abasizadeh, H. 2020. The eradication of reactive black 5 dye liquid wastes using Azolla filiculoides aquatic fern as a good and an economical biosorption agent. SN Applied Sciences, 2, 1015.

Balarak, D. \& Azarpira, H. 2016. Photocatalytic degradation of sulfamethoxazole in water: investigation of the effect of operational parameters. International Journal of ChemTech Research, 2016, 9 (12): 731-738., 9, 731-738.

Balarak, D., Mostafapour, F., Bazrafshan, E. \& Saleh, T. A. 2017. Studies on the adsorption of amoxicillin on multi-wall carbon nanotubes. Water Sci Technol, 75, 1599-1606.

Balarak, D. \& Mostafapour, F. K. 2019. Photocatalytic degradation of amoxicillin using UV/Synthesized $\mathrm{NiO}$ from pharmaceutical wastewater. Indonesian Journal of Chemistry, 19, 211-218.

Balarak, D., Mostafapour, F. K. \& Azarpira, H. 2016. Adsorption kinetics and equilibrium of ciprofloxacin from aqueous solutions using Corylus avellana (Hazelnut) activated carbon. Journal of Pharmaceutical Research International, 1-14.

Brouers, F. \& Al-Musawi, T. J. 2015. On the optimal use of isotherm models for the characterization of biosorption of lead onto algae. Journal of Molecular Liquids, 212, 46-51.

Brouers, F. \& Al-Musawi, T. J. 2020. The use of the Brouers-Sotolongo fractal kinetic equation for the study of drug release. Adsorption, 26, 843-853.

Bui, T. X. \& Choi, H. 2009. Adsorptive removal of selected pharmaceuticals by mesoporous silica SBA15. J Hazard Mater, 168, 602-8.

Çalışkan, E. \& GÖKTÜRK, S. 2010. Adsorption Characteristics of Sulfamethoxazole and Metronidazole on Activated Carbon. Separation Science and Technology, 45, 244-255.

Chang, P.-H., Li, Z., Jean, J.-S., Jiang, W.-T., Wang, C.-J. \& Lin, K.-H. 2012. Adsorption of tetracycline on 2:1 layered non-swelling clay mineral illite. Applied Clay Science, 67-68, 158-163.

Çıtak, A., ERDEM, B., ERDEM, S. \& ÖKSÜZOĞLU, R. M. 2012. Synthesis, characterization and catalytic behavior of functionalized mesoporous SBA-15 with various organo-silanes. Journal of Colloid and Interface Science, 369, 160-163.

Danalıŏlu, S. T., BAYAZIT, Ş. S., KERKEZ KUYUMCU, Ö. \& SALAM, M. A. 2017. Efficient removal of antibiotics by a novel magnetic adsorbent: Magnetic activated carbon/chitosan (MACC) nanocomposite. Journal of Molecular Liquids, 240, 589-596.

Davis, T. A., Volesky, B. \& Mucci, A. 2003. A review of the biochemistry of heavy metal biosorption by brown algae. Water Research, 37, 4311-4330.

Dhiman, N. \& Sharma, N. 2019. Batch adsorption studies on the removal of ciprofloxacin hydrochloride from aqueous solution using $\mathrm{ZnO}$ nanoparticles and groundnut (Arachis hypogaea) shell powder: a comparison. Indian Chemical Engineer, 61, 67-76.

Ebrahimi Getkesh, M., Younesi, H. \& Shahbazi, A. 2014. Nitrate Removal from Aqueous Solution Using Nanoporous MCM-41 Silica Adsorbent Functionalized with Diamine Group. Journal of Water and Wastewater; Ab va Fazilab (in persian), 25, 69-76.

Erşan, M., Bağda, E. \& Bağda, E. 2013. Investigation of kinetic and thermodynamic characteristics of removal of tetracycline with sponge like, tannin based cryogels. Colloids and Surfaces B: Biointerfaces, 104, 75-82.

Gao, J. \& Pedersen, J. A. 2005. Adsorption of Sulfonamide Antimicrobial Agents to Clay Minerals. Environmental Science \& Technology, 39, 9509-9516. 
Gao, Y., Li, Y., Zhang, L., Huang, H., Hu, J., Shah, S. M. \& Su, X. 2012. Adsorption and removal of tetracycline antibiotics from aqueous solution by graphene oxide. Journal of Colloid and Interface Science, 368, 540-546.

Guler, U. A. \& Sarioglu, M. 2014. Removal of tetracycline from wastewater using pumice stone: equilibrium, kinetic and thermodynamic studies. J Environ Health Sci Eng, 12, 79.

Heidari, A., Younesi, H. \& Mehraban, Z. 2009. Removal of $\mathrm{Ni}(\mathrm{II}), \mathrm{Cd}(\mathrm{II})$, and $\mathrm{Pb}$ (II) from a ternary aqueous solution by amino functionalized mesoporous and nano mesoporous silica. Chemical Engineering Journal, 153, 70-79.

Ho, K. Y., Mckay, G. \& Yeung, K. L. 2003. Selective adsorbents from ordered mesoporous silica. Langmuir, 19, 3019-3024.

Ho, Y.-S. 2006. Second-order kinetic model for the sorption of cadmium onto tree fern: A comparison of linear and non-linear methods. Water Research, 40, 119-125.

Huang, L., Wang, M., Shi, C., Huang, J. \& Zhang, B. 2014. Adsorption of tetracycline and ciprofloxacin on activated carbon prepared from lignin with $\mathrm{H} 3 \mathrm{PO} 4$ activation. Desalination and Water Treatment, 52, 2678-2687.

Kakavandi, B., Esrafili, A., Mohseni-Bandpi, A., Jonidi Jafari, A. \& Rezaei Kalantary, R. 2014. Magnetic Fe3O4@C nanoparticles as adsorbents for removal of amoxicillin from aqueous solution. Water Sci Technol, 69, 147-55.

Kerkez-Kuyumcu, Ö., Bayazit, Ş. S. \& Salam, M. A. 2016. Antibiotic amoxicillin removal from aqueous solution using magnetically modified graphene nanoplatelets. Journal of Industrial and Engineering Chemistry, 36, 198-205.

Khodadadi, M., Al-Musawi, T. J., Kamranifar, M., Saghi, M. H. \& Hossein Panahi, A. 2019. A comparative study of using barberry stem powder and ash as adsorbents for adsorption of humic acid. Environmental Science and Pollution Research, 26, 26159-26169.

Khoshnamvand, N., Ahmadi, S. \& Mostafapour, F. K. 2017. Kinetic and isotherm studies on ciprofloxacin an adsorption using magnesium oxide nanopartices. J Appl Pharm Sci, 7, 079-083.

Kim, S. H., Shon, H. K. \& Ngo, H. H. 2010. Adsorption characteristics of antibiotics trimethoprim on powdered and granular activated carbon. Journal of Industrial and Engineering Chemistry, 16, 344-349.

Kirik, S. D., Parfenov, V. A. \& Zharkov, S. M. 2014. Monitoring MCM-41 synthesis by X-ray mesostructure analysis. Microporous and Mesoporous Materials, 195, 21-30.

Kuśmierek, K. \& Świątkowski, A. 2015. The influence of different agitation techniques on the adsorption kinetics of 4-chlorophenol on granular activated carbon. Reaction Kinetics, Mechanisms and Catalysis, 116, 261-271.

Lam, K. F., Chen, X., Mckay, G. \& Yeung, K. L. 2008. Anion Effect on Cu2+ Adsorption on NH2MCM-41. Industrial \& Engineering Chemistry Research, 47, 9376-9383.

Lam, K. F., Yeung, K. L. \& Mckay, G. 2006. An investigation of gold adsorption from a binary mixture with selective mesoporous silica adsorbents. J Phys Chem B, 110, 2187-94.

Li, S., Zhang, X. \& Huang, Y. 2017. Zeolitic imidazolate framework-8 derived nanoporous carbon as an effective and recyclable adsorbent for removal of ciprofloxacin antibiotics from water. Journal of Hazardous Materials, 321, 711-719.

Liu, W., Zhang, J., Zhang, C. \& Ren, L. 2011. Sorption of norfloxacin by lotus stalk-based activated carbon and iron-doped activated alumina: Mechanisms, isotherms and kinetics. Chemical Engineering Journal, 171, 431-438.

Mahvi, A. H., Mostafapour, F. K. \& Balarak, D. 2018. Biosorption of tetracycline from aqueous solution by azolla filiculoides: equilibrium kinetic and thermodynamics studies. Fresenius Environmental Bulletin, 27, 5759-5767.

Martin, T., Galarneau, A., Brunel, D., Izard, V., Hulea, V., Blanc, A. C., Abramson, S., Di Renzo, F. \& Fajula, F. 2001. 29-O-02 Towards total hydrophobisation of MCM-41 type silica surface. In: GALARNEAU, A., FAJUlA, F., DI RENZO, F. \& VEDRINE, J. (eds.) Studies in Surface Science and Catalysis. Elsevier. 
Miranda, C. D., Godoy, F. A. \& Lee, M. R. 2018. Current Status of the Use of Antibiotics and the Antimicrobial Resistance in the Chilean Salmon Farms. Front Microbiol, 9, 1284.

Mohammed, A. A., Al-Musawi, T. J., Kareem, S. L., Zarrabi, M. \& Al-Ma'abreh, A. M. 2020a. Simultaneous adsorption of tetracycline, amoxicillin, and ciprofloxacin by pistachio shell powder coated with zinc oxide nanoparticles. Arabian Journal of Chemistry, 13, 4629-4643.

Mohammed, A. A., Atiya, M. A. \& Hussein, M. A. 2020b. Simultaneous studies of emulsion stability and extraction capacity for the removal of tetracycline from aqueous solution by liquid surfactant membrane. Chemical Engineering Research and Design, 159, 225-235.

Mohammed, A. A., Najim, A. A., Al-Musawi, T. J. \& Alwared, A. I. 2019. Adsorptive performance of a mixture of three nonliving algae classes for nickel remediation in synthesized wastewater. Journal of Environmental Health Science and Engineering, 17, 529-538.

Moussavi, G., Alahabadi, A., Yaghmaeian, K. \& Eskandari, M. 2013. Preparation, characterization and adsorption potential of the $\mathrm{NH} 4 \mathrm{Cl}$-induced activated carbon for the removal of amoxicillin antibiotic from water. Chemical Engineering Journal, 217, 119-128.

Nasseh, N., Al-Musawi, T. J., Miri, M. R., Rodriguez-Couto, S. \& Hossein Panahi, A. 2020. A comprehensive study on the application of FeNi3@SiO2@ZnO magnetic nanocomposites as a novel photo-catalyst for degradation of tamoxifen in the presence of simulated sunlight. Environmental Pollution, 261, 114127.

Nasseh, N., Khosravi, R., Rumman, G. A., Ghadirian, M., Eslami, H., Khoshnamvand, M., Al-Musawi, T. J. \& Khosravi, A. 2021. Adsorption of $\mathrm{Cr}(\mathrm{VI})$ ions onto powdered activated carbon synthesized from Peganum harmala seeds by ultrasonic waves activation. Environmental Technology \& Innovation, 21, 101277.

Nguyen, C. \& Do, D. D. 2001. The Dubinin-Radushkevich equation and the underlying microscopic adsorption description. Carbon, 39, 1327-1336.

Parsa, J. B., Panah, T. M. \& Chianeh, F. N. 2016. Removal of ciprofloxacin from aqueous solution by a continuous flow electro-coagulation process. Korean Journal of Chemical Engineering, 33, 893901.

Peng, X., Hu, F., Dai, H., Xiong, Q. \& Xu, C. 2016. Study of the adsorption mechanisms of ciprofloxacin antibiotics onto graphitic ordered mesoporous carbons. Journal of the Taiwan Institute of Chemical Engineers, 65, 472-481.

Peterson, J. W., Petrasky, L. J., Seymour, M. D., Burkhart, R. S. \& Schuiling, A. B. 2012. Adsorption and breakdown of penicillin antibiotic in the presence of titanium oxide nanoparticles in water. Chemosphere, 87, 911-7.

Rahardjo, A. K., Susanto, M. J. J., Kurniawan, A., Indraswati, N. \& Ismadji, S. 2011. Modified Ponorogo bentonite for the removal of ampicillin from wastewater. Journal of Hazardous Materials, 190, 1001-1008.

Rostamian, R. \& Behnejad, H. 2016. A comparative adsorption study of sulfamethoxazole onto graphene and graphene oxide nanosheets through equilibrium, kinetic and thermodynamic modeling. Process Safety and Environmental Protection, 102, 20-29.

Samarghandi, M. R., Al-Musawi, T. J., Mohseni-Bandpi, A. \& Zarrabi, M. 2015. Adsorption of cephalexin from aqueous solution using natural zeolite and zeolite coated with manganese oxide nanoparticles. Journal of Molecular Liquids, 211, 431-441.

Serwecińska, L. 2020. Antimicrobials and Antibiotic-Resistant Bacteria: A Risk to the Environment and to Public Health. Water, 12, 3313.

To, M.-H., Hadi, P., Hui, C.-W., Lin, C. S. K. \& Mckay, G. 2017. Mechanistic study of atenolol, acebutolol and carbamazepine adsorption on waste biomass derived activated carbon. Journal of Molecular Liquids, 241, 386-398.

Wang, F., Yang, B., Wang, H., Song, Q., Tan, F. \& Cao, Y. 2016. Removal of ciprofloxacin from aqueous solution by a magnetic chitosan grafted graphene oxide composite. Journal of Molecular Liquids, 222, 188-194. 
Yokoi, T., Kubota, Y. \& Tatsumi, T. 2012. Amino-functionalized mesoporous silica as base catalyst and adsorbent. Applied Catalysis A: General, 421-422, 14-37.

Yu, F., Li, Y., Han, S. \& Ma, J. 2016. Adsorptive removal of antibiotics from aqueous solution using carbon materials. Chemosphere, 153, 365-385.

Zha, S., Zhou, Y., Jin, X. \& Chen, Z. 2013. The removal of amoxicillin from wastewater using organobentonite. J Environ Manage, 129, 569-76.

Zhang, L., Song, X., Liu, X., Yang, L., Pan, F. \& Lv, J. 2011. Studies on the removal of tetracycline by multi-walled carbon nanotubes. Chemical Engineering Journal, 178, 26-33.

Zhao, Y., Tong, F., Gu, X., Gu, C., Wang, X. \& Zhang, Y. 2014. Insights into tetracycline adsorption onto goethite: Experiments and modeling. Science of The Total Environment, 470-471, 19-25. 
Conflict of interest statement: On behalf of all authors, the corresponding author states that there is no conflict of interest.

With warm regards

Sincerely

Davoud Balarak

Email: $\underline{\text { dbalarak2@gmail.com }}$

Corresponding Author 